\title{
Numerical Model and Validation Experiments of Atrium Enclosure Fire in a New
}

\section{Fire Test Facility}

Authors: Cándido Gutiérrez-Montes ${ }^{\mathrm{a}, *}$, Enrique Sanmiguel-Rojas ${ }^{\mathrm{a}}$, Antonio S. Kaiser ${ }^{\mathrm{b}}$ and Antonio Viedma $^{\mathrm{b}}$

${ }^{a}$ Fluid Dynamics Division of the Department of Mining and Mechanical Engineering, University of Jaen, Jaen, Spain

${ }^{b}$ Department of Thermal and Fluid Engineering, Technical University of Cartagena, Murcia, Spain

*Corresponding author. Tel.: +34 953212871; fax: +34 953212870

E-mail address: cgmontes@ujaen.es

\section{Postal address:}

aÁrea de Mecánica de Fluidos, Dpto. Ingeniería Mecánica y Minera

Universidad de Jaén, Campus de las Lagunillas, Edificio A3. Despacho 067, 23071 Jaen, Spain

bárea de Mecánica de Fluidos, Dpto. Ingeniería Térmica y de Fluidos

Universidad Politécnica de Cartagena, C/ Dr. Fleming, s/n (Campus Muralla), 30.202 Cartagena, Murcia, Spain

\begin{abstract}
The use of CFD as a tool for buildings, warehouses or factories design requirements fulfilling about fire safety is becoming more common and reliable. Performance-based fire safety assurance procedures make use of the CFD fire modelling to anticipate the evolution of fire, but they need always to be validated. This is especially difficult for big structures, with great clear volumes, where effects of natural and forced ventilation can be very scale dependent. A good opportunity to check the prediction capability of CFD codes to establish temperatures and velocities fields is the new full-scale fire test facility of the Technological Metal Centre in Murcia, Spain. It is an aluminium prismatic squared base building of 19.5 $\mathrm{m} \times 19.5 \mathrm{~m} \times 20 \mathrm{~m}$, with several vents arranged in its walls and four exhaust fans at the roof. Series of experimental tests have been carried out using several heptane normalized pool-fires placed at the centre of the atrium. The data obtained from these experiments have been later used in a validation study of two
\end{abstract}


CFD simulations implemented for temperature wall, ambient temperature prediction and exhaust fan assessment. The results show good agreement between experimental and numerical predictions and allow concluding that for a fire test of 1.6 MW of average heat release power, the exhaust and ventilation system is not enough to extract the hot combustion products. There is an excessive and dangerous accumulation of hot gases at the upper part of the atrium and the exhaust capacity of the roof fan must be increased. The CFD models can give the answer to that question.

Keywords: CFD, Fire modelling, Large building, Fire test, Smoke exhaust.

\section{Introduction}

Since the beginning of fire studies in the 60's, many lines of research have been followed and, as a consequence, the phenomenological understanding of fires has increased considerably [1].

At the last decades, a great part of this understanding comes from the results and conclusions obtained from numerical studies carried out thanks to the rapid development and advances of computational power. The computational fluid dynamics (CFD) based field models are becoming more and more useful, even during the design process.

As a result of this, a shift has occurred from the engineering application of correlation-based methods, such as zone methods, to the Navier-Stokes equations helped by the computational fluid dynamics (CFD) techniques. These advances and developments have effects over building codes, regulations and standards with the gradual movement away from the usual prescriptive-based to more performance-based methodologies and codes [2-4]. So, thanks to this, an optimal degree of protection can be obtained. Here, to solve fire-related problems, fire engineers are given the freedom to employ innovative design, with the aim of more efficient use of space, building materials, and more cost-effective solutions. 
The great complexity of some CFD-based fire models, which take into account turbulence, combustion, radiation and soot sub-models [5], entails more accurate results obtained for fire simulation. However, these models have to be validated, with experimental data, in order to acquire confidence in its usage. Only after comparing the experimental results with numerical outputs and verifying their agreement, the CFD model predictions can be used to help the design of effective protection systems for hazardous areas [6] or to set fire safety attributes for building maintenance [7].

At the field of enclosure fires there is a wide range of sizes and distributions, but three groups could be defined: small single-rooms, multi-rooms and big rooms/buildings or atria. The present work deals with the third group, it means, large space buildings' fires. Although it is not a new architectural feature, large space buildings are more and more popular overalls in big cities. In the last decades, semi-hollow of great dimensions buildings have been more commonly constructed such as atria, covered shopping malls, convention centres, airport terminals, sport arenas and warehouses. So it is very important to know how a fire that takes place inside of one of these structures develops and to know the effects and hazards that it can cause inside.

Studies about fires in large space buildings have been done during the last twenty years by many researches in several ways. From the 80 's, it can be mentioned the experiments performed by Yamana et al. [8] or the numerical studies like the one carried out by Chow [9]. Chow et al. [10,11] continued studying fire-induced flow and smoke spread in large space buildings, both experimentally and numerically [12]. Lu et al. $[13,14]$ simulated the flow inside refuges floor within a high-rise building. More recently, Cui et al. [15] have study the fire-induced fluid flow in an atrium. He et al. [16] studied fire-induced conditions in an industrial warehouse. Qin et al. [17] have carried out the performance of different smoke exhaust methods and have analysed fire-induced smoke movement in a real gymnasium, as it also have done Jianguo et al. [18]. Also, Ding et al. [19] have approached numerically and experimentally, at reduced-scale, the possibility of using the same system for solar-assisted natural ventilation and smoke control in a prototype atrium building, and again Chow et al. [20] have tackled fire-induced smoke problems in green and sustainable buildings. 
Many reduced-scale experiments have been carried out $[19,21]$ as validation tests of these numerical models. But full-scale fire experiments [16, 22-25] are important as it is not easy to preserve the similarities between reduced scale models with real fires. There is only a few of full-scale fire data sets because it is very expensive, sometimes prohibitive to obtain them.

The present work deals with these two subjects: a new full scale facility in an atrium enclosure is presented and two CFD fire simulations are developed to evaluate air and combustion gases movement in its interior.

The data obtained from the fire experiments will be used to validate the numerical simulations developed using the commercial finite volumes CFD code, FLUENT, that simulates properly the fire-induced flow in the atrium, and which would be applicable to other similar buildings.

As it is generally known, smoke and heat are the main dangerous factors that can cause death in an indoor fire. For this reason, a study of the smoke exhaust/ventilation system of the "Fire Atrium" is, finally, carried out and alternative ventilation hypothesis are assessed, proving how valuable the CFD has become as design tool.

\section{Test facility and instrumentation}

The fire tests have been carried out at the "Fire Atrium", figure 1, of the Technological Metal Centre, in Murcia, Spain. This full-scale burning facility is an aluminium prismatic structure, figure 2, which dimensions are $19.5 \mathrm{~m} \times 19.5 \mathrm{~m} \times 17.5 \mathrm{~m}$. It also has a pyramidal shaped roof of $2.5 \mathrm{~m}$ high with four exhaust fans. The total high is, therefore, of $20 \mathrm{~m}$. The walls are made of $6 \mathrm{~mm}$ thick aluminium sheet. There are several grilled vents arranged at the lower part of the walls.

This 'Fire Atrium' was originally constructed to check fire-extinguisher efficiency and to help to optimize its design. The fire pools, or other fire containers, are placed in the centre of the square atrium floor for the tests. It has been used pool fires for the tests because they represent one of the most frequent 
accidents in the processing industries and in the transport hazardous substances [26], and it is easy to calculate the calorific power released during the tests. Three different normalized pools of different diameters were used ( $21 \mathrm{~b}$ pool has a diameter of $0.92 \mathrm{~m}, 34 \mathrm{~b}$ pool has a diameter of $1.17 \mathrm{~m}$ and $70 \mathrm{~b}$ pool has a diameter of $1.67 \mathrm{~m}$ ), ranging an average heat release between 1.4 and 5.5 MW.

The atrium has been equipped with temperature, pressure and velocity sensors, in order to study the thermal and fluid fields induced by the fire. Up to sixty one sensors have been installed, measuring walls and roof metal temperature, and air temperature in several sections: next to the walls, central plane, through the exhaust fans and through inlet vents. Differential and absolute pressure taps at the exhaust fans have been also mounted to calculate, from fan performance curves, the mass and volume flow rate evacuated.

For discussion, all this measuring equipment can be grouped in four different zones, which are described below:

- Wall A: with a total of nineteen sensors. Four of them measure wall metal temperature taps. Another nine control air temperature sensors at thirty centimetres from the wall. Finally, as there are three grilled vents in wall $\mathrm{A}$, there are one temperature and one velocity sensor at each one, see figure 3.

- Wall C: with eighteen sensors: four wall temperature sensors, ten air temperature sensors close to the wall, and it also one temperature sensor and one velocity sensor at each of the two vents of this side, see figure 4.

- Central section: has twelve air temperature sensors set up in three different heights, see figure 5 a). This mean plane contains some temperature sensor inside the plume inducted by the fire.

- Finally, there are twelve more sensors set up at the roof, see figure $5 \mathrm{~b}$ ). Six of them measure roof temperature. At the exhaust fan close to wall $\mathrm{A}$ and wall $\mathrm{C}$ there are set up one absolute pressure sensor, 
one differential pressure sensor and one air temperature sensor in each one, in order to measure the mass flow rate leaving the atrium and its temperature.

Three different types of Pt100 probes, with range of $393.15 \mathrm{~K}, 423.15 \mathrm{~K}$ and $773.15 \mathrm{~K}$, respectively, were used to measure air temperature through vents, next to walls and through exhaust fans. Three different Type-k thermocouples, with range of $473.15 \mathrm{~K}, 1073.15 \mathrm{~K}$ and $1773.15 \mathrm{~K}$, respectively, were used to measure walls, roof and air temperature at the central section. At the vents, were used hot wire anemometers to measure air velocity, with a range up to $2 \mathrm{~m} / \mathrm{s}$. Differential and absolute pressure, at the exhaust fans, were measured by two Kimo's pressure transmitters. The weather conditions are recorded using a meteorological station. Finally, a Modicom TSX Premium automaton was used to register the data.

An uncertainty analysis for the measurements of temperature, velocity and air flow through the exhaust fans has been attached in Appendix A.

\section{Numerical model}

Numerical simulations have been carried out using the commercial CFD code Fluent, based on finite volumes method. They have been performed in a steady state employing a segregated solver. The equations have been discretized on finite-volumes, using a second order 'upwind' discretization scheme [27] for the convective terms of the equations. The SIMPLE algorithm [28, 29] has been used to solve the coupling between continuity and momentum equations through pressure. The PRESTO! scheme has been used to discretize the momentum equation, which is similar to the staggered-grid schemes used with structured meshes [29]. The simulations are considered to be converged when all the residuals of each variable are lower than $10^{-5}$, and the flows imbalance of mass and heat transfer rate are lower than $0.1 \%$, see figure 6 and table 1. 
Two quasi-structured 3D grids have been used: a 180,000 cells grid for a "no combustion" numerical simulation (see figure 7), and a finer one of 300,000 cells grid for a "combustion" numerical simulation. The grids have been stretched near the thermal source and near the exhaust fans.

In both simulations, the next models have been used:

The standard k- $\varepsilon$ turbulence model [30], which has been applied and validated to predict the smoke movements in compartments [31], atria [32], unconfined pool fires [33], etc, demonstrating that the k- $\varepsilon$ type of turbulence model $[31,34-36]$ is still a practical approach for simulating fire-induce air flow as the required CPU time is relatively short.

To simulate radiation it has been used the $\mathrm{P} 1$ radiation model. This model is the simplest case of the more general P-N model, which is based on the expansion of the radiation intensity into an orthogonal series of spherical harmonics [37, 38]. Although P1 model tends to over predict radiative fluxes from localized heat sources or sinks [39], it has been used with good results in combustion appliances [40, 41]. For thermal applications where the optical thickness is larger than one, as in the present paper, it works reasonably well [42], achieving good accuracy with little CPU demanding.

Several non-controllable asymmetries were found during the experiments, like the one from the external wind at the vents, which have not been borne in mind. These are some of the reasons of the discrepancies found between experimental data and numerical results.

For the velocity and the temperature it has been employed wall-laws. A mixed heat transfer model, which takes into account the convective and radiative heat interchange with the ambient, has been set for the walls and the roof. The free stream temperature is equal to the ambient temperature measured with the meteorological station and it has been set a value of 0.3 as the aluminium emissivity. A radiation heat transfer model has been used for the ground where 0.96 has been set as the cement emissivity. 
The vents at the walls have been supposed to be ambient air inlets which generate pressure losses equal to the 30 per cent of the dynamic pressure. For the exhaust fans it has been set the numerical equation (static pressure versus flow) given by its manufacturer, see figure 19.

Next, two different approaches for the heptane's pool fire are described:

a) No combustion simulation (simulation 1).

The fire has been simulated as a thermal source that consists of a cylindrical surface placed at the centre of the base of the atrium, see figure 8 , which temperature is similar to the heptane's adiabatic flame temperature calculated on the basis of its stoichiometric combustion, approximately $1770 \mathrm{~K}$ [43]. The cylindrical surface has the same diameter, $D$, as the one of the used pool-fire, and its height, $H$, is determined as the height of the combustion zone $[44,45]$ given by the next expression:

$$
(13.8-2.15) F_{f}^{2 / 3} \leq \frac{H}{D} \leq(13.8+2.15) F_{f}^{2 / 3}
$$

where, $F_{f}$, is the fuel Froude number,

$$
F_{f} \equiv \frac{\dot{m}}{\rho_{a} \sqrt{g D}}
$$

introduced by Thomas [46], where $\rho_{a}$ is the ambient density and $\dot{m}[47,48]$ is the mean burning rate which is defined as

$$
\dot{m} \equiv \frac{4 \rho_{f} V_{f}}{\Delta t \pi D^{2}}
$$

where $\rho_{f}$ is the fuel density, $684 \mathrm{~kg} / \mathrm{m}^{3}, V_{f}$ is the volume of fuel burned at each experiment and $\Delta t$ is the experiment duration.

The expression (1) is valid for pool diameters from $0.3 \mathrm{~m}$ to $6 \mathrm{~m}$ and $H / D$ from 0.45 to 0.75 . For the hearth $21 \mathrm{~b}$, the mean burning rate is $\dot{m}=0.054 \mathrm{~kg} /\left(\mathrm{s} \mathrm{m}^{2}\right), F_{f}=0.0150$ and $H$ can vary from $0.708 \mathrm{~m}$ to $0.970 \mathrm{~m}$. It has been set a height equal to $0.71 \mathrm{~m}$. 
Although real flow consists of air and smoke, it has been employed a one specie flow to achieve simplicity and low computational cost, assuming ideal gas law for density and three coefficients Sutherland law for viscosity. In order to take into account combustion products and radiative effects, it has been set an average value between air and smoke of 0.37 for the absorption coefficient, calculated from [49].

\section{b) Combustion simulation (simulation 2).}

In this case the fire has been simulated with a combustion model. In non-premixed combustion, the fuel and oxidizer are initially contained in separate streams, as it occurs in pool fires. When the mixing time scale is much longer than the reaction time scale, local instantaneous chemistry can be assumed. The nonpremixed modelling approach is suitable for the simulation of turbulent diffusion flames with fast chemistry $[42,50,51]$.

This method is based on the work of Burke et al. [52], under the assumptions of equal species diffusion coefficients, Lewis number equal to one and low Mach number. Under these conditions it can be assumed that instantaneous thermo-chemical state of the fluid is related to a conserved scalar quantity and the mixture fraction, defined as

$$
f \equiv \frac{m_{f}}{m_{f}+m_{o x}},
$$

where $m_{f}$ is the fuel mass and $m_{o x}$ is the mass of oxidant.

In this way, the species transport equations can be reduced to a transport equation for the mixture fraction and for its variance. The advantage of the mixture fraction is that any other conserved scalar, that is a function of $f$ such as the density, or the mass fraction of a given element, can be calculated from the local value of $f$ and its variance $\bar{f}^{\prime 2}$. The thermochemistry calculations are preprocessed and then tabulated for look-up in Fluent. Interaction of turbulence and chemistry is accounted for with an assumedshape Probability Density Function (PDF). For this model the $\beta$-function has been used. 
The non-premixed model allows intermediate species prediction, dissociation effects, and rigorous turbulence-chemistry coupling. The method is also computationally efficient as it does not require the solution of a large number of species transport equations.

For the present work 12 species have been considered. The pool-fire has been simulated as a constant mass flow injection rate of vaporized heptane equal to the mass flow rate measured, through a circle in the floor with the same diameter $(\mathrm{D}=0.92 \mathrm{~m})$ of the real pool-fire, see figure 9.

\section{Results and discussion}

Although several fire tests with different fire powers have been performed, all the data presented in this paper belong to the same case, chosen as a characteristic example of the flow and temperature field produced in the "Fire Atrium". The experimental case presented was held in November $19^{\text {th }} 2003$, under conditions of soft wind, atmospheric pressure of 1018 mbar and ambient temperature of $290.15 \mathrm{~K}$.

It was used a normalized pool-fire (hearth 21b) placed at the centre of the floor. At this test 44 litres of heptane were burned during $837 \mathrm{~s}$, see figure 10, generating an estimated average heat release power of 1.6 MW. The HRR is computed from the mass loss rate of fuel measured by an electronic balance during the burning process, with deviation of about 5\%. As it can be seen in figure 11 a constant HRR is early reached.

Quasi-steady conditions were considered from time equal to $780 \mathrm{~s}$, approximately, as the measures show little variations, see figure 12. For this experiment all vents were open and all the exhaust fans running.

Models' validation has been carried out comparing experimental data obtained from the test described before with predicted results from both numerical simulations with experimental conditions being reproduced. Below, it is shown the comparison of the temperature results for the roof, the air through the exhaust fans, the walls and the air next to them as well as at the central section. Also it has been compared 
the flow through the fans and the velocities at the vents. Finally, a description of the flow field main characteristics is presented.

$\underline{\text { Roof: }}$

Numerical results show good agreement with experimental data. Maximum difference between experimental and numerical data is $\Delta \mathrm{T} \sim 8 \mathrm{~K}$ for air temperature and $\Delta \mathrm{T} \sim 7 \mathrm{~K}$ for the roof temperature, see figure 13. There are short differences in air temperature through exhaust fans and a little higher at the temperatures given by the CFD models. This is due to the plume inclination obtained, as it happens in actual experimental test.

Also, it can be seen how this asymmetry is smaller at the combustion model simulation as this model reproduces more accurately the heptane's combustion involving higher temperatures that induce a higher inertia to the smoke and so being the plume less affected by the asymmetric vents layout.

$\underline{\text { Walls: }}$

Wall temperatures obtained numerically show a maximum difference respect to measured experimental data of $\Delta \mathrm{T} \sim 10 \mathrm{~K}$, see figure 14. Similar wall temperature profiles are obtained numerically. It can be seen how the use of a combustion model generates a less uniform temperature field due to the dynamic nature of the real fire. Numerically it is also observed a little temperature increment as we move to the left side of the wall, due to the inclination of the plume, being this effect more important at the simulation 1 , as it has been mentioned before. This effect is more evident at the upper part of the wall, while the lines of equal temperature are more horizontal at the lower region. The reason for this is that the vents at the lower portion of the walls that allow the fresh air to enter and to homogenize the temperature field. These vents are not distributed symmetrically leading to a lack of verticality of the plume and the nonuniformity of the flow at the upper zone of the atrium.

Air close to walls: 
In figure 15 it is showed the air temperature close to wall C. It is observed a stratification of the temperature with height, both in experimental and numerical results. A comparison between experimental and numerical results shows a maximum difference lower than $\Delta \mathrm{T} \sim 3 \mathrm{~K}$ at the heights of 10 and 15 metres. At 5 metres of high there are differences of $\Delta \mathrm{T} \sim 9 \mathrm{~K}$. This relative higher difference can be due to the fact that, at lower zones, heat transfer is mainly due to radiation and the radiative model and the outer fresh air has more influence. At higher zones the plume convective heat transport is the dominant effect and the numerical prediction is more accurate.

Again, it can be seen how the simulation 2 shows a less uniform and so more realistic temperature field profile that shows the dynamic characteristics of the different temperature and species concentration layers due to the mixing processes between them added to the effect of the plume, fans and vents.

\section{$\underline{\text { Central section: }}$}

The plume obtained is asymmetric, see figure 16 , due to the asymmetry of the air intake vents layout. This effect has been also checked visually. A comparison between experimental and numerical temperatures over the central section show good agreement in general, except for the simulation 1 near the fire, where it behaves worse. The inclusion of a combustion model, not only allows to reproduce more realistically the different temperature layers, but also allows to reproduce more accurately the flow near the fire.

Exhaust fans:

In table 2, experimentally measured and numerically predicted air flow through exhaust fans are showed. There is a maximum difference of $0.5 \mathrm{~m}^{3} / \mathrm{s}$. These discrepancies may be due to the fact that exhaust fans have been numerically placed parallel to the roof to simplify the mesh process when they are actually parallel to the ground. Both experiments and numerical simulations show that exhaust fan E1 works less 
than $E 3$. This can be due to the pressure gradient at the roof generated by the inclination of the plume caused by an asymmetric intake of outer fresh air.

Vents:

As well as temperature field, it has also been compared experimental with numerical air velocity at vents, achieving a good matching, see table 3 . The measured air velocity results are given within a range due to turbulence unsteady effects.

\section{$\underline{\text { General flow field: }}$}

The Fluent simulation results for velocity flow field can give a view of the general structure of the flow produced in the atrium. The figure 17 shows an asymmetric plume over the thermal source, where convection-induced buoyancy generates, at the exhaust fans, velocities between $6-14 \mathrm{~m} / \mathrm{s}$, for the simulation 1 , and between $6.5-15 \mathrm{~m} / \mathrm{s}$, for the simulation 2 . As it has been mentioned before, the higher temperatures and velocities predicted by the simulation 2 , near the flame, generates a more axisymmetric plume than in the simulation 1.

Numerically, it has been also observed that as the hot air from the plume reaches the roof, is not completely evacuated by the exhaust fans. Part of this air flow recirculates parallel to the roof towards the walls and descend close to them. This descending flow reaches the vents and an outward hot flow can be detected at the upper portion of each vent, see figure 18.

In Appendix B it can be found summarized the temperature values obtained at the experiment.

\section{Alternative fans study}

The full-scale experiment and the numerical simulations discussed above indicate that the exhaust fans at the roof are not able to evacuate all the hot gases produced by the pool fire. The pool used (hearth $21 \mathrm{~b}$ ) is 
one of the smallest that can be set at the atrium according to extinguisher test standards. The accumulation of the hot gases produces an air temperature and wall increase than can damage the facility and the measuring instruments. This great inconvenience, in such a useful fire facility, limits its operation possibilities. It is clear due to a wrong mechanical exhaust system choice. In another construction with people, this situation would be very dangerous, as smoke and heat are the main factors that cause death in indoor fires.

Smoke exhaust system is therefore one of the most important aspects in fire safety design. The goal of the smoke exhaust system is to ensure that the impact of smoke and heat on people is not life threatening [53]. Ideally, it should ensure that height of the smoke layer is kept above the highest level of occupants and temperature is low enough for a defined period of time, so as to allow sufficient time for evacuation from the building.

To give an insight on the efficiency of mechanical exhaust of the smoke from the fire, different fans have been studied using the model of combustion included in the simulation 2, which as turned out to be able to reproduce more accurately the real conditions induced by a fire. The present fans have a diameter of $0.56 \mathrm{~m}$. Three alternatives have been considered and numerically simulated. The first one, just to obtain natural exhaust capacity, is to take out the fan and let the four opening at the roof. The other two are with similar fans of larger diameter and flow capacity:

- Alternative 1: open natural ventilation, same diameter without fans.

- $\quad$ Alternative 2: $\mathrm{D}=0.8 \mathrm{~m}$ exhaust fans.

- $\quad$ Alternative 3: $\mathrm{D}=1 \mathrm{~m}$ exhaust fans.

The exhaust fans characteristic curves are showed in figure 19.

The experimental and predicted outflow through the exhaust exits are showed in table 4 . In all cases, the average fire heat release used is the same as the used at the validation study, 1.6 MW. 
As expected, the flow increases with the capacity of the fans. For the highest diameter considered, the flow is almost ten times the naturally evacuated with the present openings. Also it can be appreciated that the installed exhaust fans $(0.56 \mathrm{~m})$ are working at peak flow (see figure 19), meanwhile the other two exhaust fans are working at the middle zone of the performance curve, being able to pump out more flow if needed.

The main change expected with larger fans is the reduction of temperatures and recirculation inside the atrium. In figure 20 the predicted wall temperatures can be compared. The wall temperature decrease with the use of the alternative fans is very significant. The largest fans reduce the recirculation flow at the roof, see figure 21, and there is a smaller flow of hot gases coming down the walls to the walls grilled vents. In fact, this outflow disappears when $1 \mathrm{~m}$ diameter exhaust fans are used, see figure 22. Due to the large volume of the "Atrium" there will appear low speed flow zones where the flow might become laminar; in these regions the turbulence model used at the present work could not be predicting very accurate results so this will have to be taken into account in future works. Finally, the predictions also show how the use of the bigger fans, make the smoke layer height becomes higher and the temperature rises lower. In the figure 23 , it is showed the temperature and carbon dioxide mole concentration within a vertical line located at coordinates $[\mathrm{x}=14.625 \mathrm{~m} ; \mathrm{y}=14.625 \mathrm{~m}]$. According to this figure, while the smoke layer height was around $7 \mathrm{~m}$ high with the $0.56 \mathrm{~m}$ fans, its height increases up to around $11 \mathrm{~m}$ high with the $0.80 \mathrm{~m}$ ones and up to nearly $17 \mathrm{~m}$ high with the $1 \mathrm{~m}$ diameter fans, assuring a higher and safer clear height in case of a fire. Also, as it has been mentioned before, the temperature of the smoke layer decreases considerably, being the possible thermal structural damage reduced.

\section{Conclusions}

Two steady numerical simulations (without and with combustion model) have been carried out to study flow generated by an enclosure fire in atria using the finite volumes code Fluent. The predicted results have been compared with experimental data obtained from a fire experiment with a heptane pool-fire of $0.92 \mathrm{~m}$ diameter and a heat release rate of 1.6 MW performed in a new full-scale burning facility, the 
'Fire Atrium' of the ‘Technological Metal Centre', in Murcia, Spain. Good matching between experimental and numerical data has been found.

Due to its unsteady nature, it is not possible to obtain a steady solution for a fire in a big volume building. Despite this, quasi-steady solutions that show quite realistic fire scenarios can be achieved. Both simulations reproduce the conditions induced by the fire. The non combustion simulation can be considered a good first approach for this problem as it is very simple and do not requires large CPU computation time and resources but, on the other hand, it cannot predict properly the conditions near the flame and also smoothes too much the temperature and flow fields predicted. The use of a combustion model adds more computational cost but also adds more realism to the numerical simulation. It can predict the entire fire induced conditions including different species, reproducing the different layers mixing processes and simulating more accurately the heptane pool-fire combustion.

Besides, the following concluding remarks can be made:

- Temperature discrepancies found between experimental and numerical temperature results are lower than $10 \mathrm{~K}$ except at the closest points to the fire, in which the non combustion simulation has showed not good agreement with the experimental data.

- Numerical results show that the exhaust fans installed up are insufficient to pump out all the hot gases products of the heptane combustion. This cause a blocking of the smoke output through the roof and a general environment temperature rise and a smoke layer growth. When this hot smoke from the plume contacts the roof, the flow inertia and colder roof contact produce a recirculation and descend of part of this flow that finally goes out though the top of the vents.

- As well, experimental pressure measure at the exhaust fans shows that they are working at peak flow and are insufficient for the hot gases generated. This means that at higher power fire the accumulation of hot gases can be dangerous and even cause the damage of the construction frame. 
- Finally, a parametric study of the performance of different exhaust fans has been carried out showing the different conditions generated by the same fire. This work demonstrates that CFD can be a valuable tool in this type of building design. It can be very useful for predicting fire-induced conditions, showing the location of the highest temperature or smoke concentration points, making possible to select appropriated ventilation and smoke exhaust systems, fire extinction system, helping to locate the emergency exits, helping to design a good evacuation procedure, etc. And all this, at a much lower cost compared to the expensive experimental facility, like the one used. This CFD analysis minimizes any possible design error that can be very expensive to rectify, and help to make the building safer and reliable.

\section{Acknowledgements}

The authors want to acknowledge the Technological Metal Centre of Murcia for the use of their test rigs, the SAIT (Technological Research Services of the Technical University of Cartagena) and the University of Jaen for the use of their entire computing resources and their technical support. This work has been supported by Ministerio de Edución y Ciencia of Spain (grants DPI2005-08654-C04-01 and TRA200615015).

\section{Appendix A: Calculation of measurements uncertainties.}

The uncertainty analysis must take into account all the elements within the measurement chain. At the experimental set up each sensor was connected to a 4-20 mA converter. Each of these converters was finally connected to an input PLC module TSX AEY 1600. A basic scheme can be seen at figure A1, where $T_{R}, P_{R} y V_{R}$ are the real temperature, pressure and velocity, respectively. $S_{T}, S_{P}$ and $S_{V}$ are the temperature, pressure and velocity sensors. Finally, T, P and V are the temperature, pressure and velocity measurements.

So, the error propagation will be defined as:

$$
\begin{aligned}
& T=T_{R}\left(1+\Delta_{S}^{T}\right)\left(1+\Delta_{C}\right)\left(1+\Delta_{A}\right)=T_{R}\left(1+\Delta_{S}^{T}+\Delta_{C}+\Delta_{A}\right)+H O T_{T} \\
& P=P_{R}\left(1+\Delta_{S}^{P}\right)\left(1+\Delta_{C}\right)\left(1+\Delta_{A}\right)=P_{R}\left(1+\Delta_{S}^{P}+\Delta_{C}+\Delta_{A}\right)+H O T_{P}
\end{aligned}
$$




$$
V=V_{R}\left(1+\Delta_{S}^{V}\right)\left(1+\Delta_{C}\right)\left(1+\Delta_{A}\right)=V_{R}\left(1+\Delta_{S}^{V}+\Delta_{C}+\Delta_{A}\right)+H O T_{V}
$$

where $\Delta_{S}^{T}, \Delta_{S}^{P}$ and $\Delta_{S}^{V}$ are the uncertainties of the temperature, pressure and velocity sensors, and $\Delta_{C}, \Delta_{A}$ are the converters and PLC uncertainties. The HOT term is composed of high order terms.

Neglecting the $H O T$ terms, the real measured data could be expressed as:

$$
\begin{aligned}
& T=T_{R}\left(1+\Delta_{T}\right) ; \text { where } \Delta_{T}=\Delta_{S}^{T}+\Delta_{C}+\Delta_{A}, \\
& P=P_{R}\left(1+\Delta_{P}\right) ; \text { where } \Delta_{P}=\Delta_{S}^{P}+\Delta_{C}+\Delta_{A}, \\
& V=V_{R}\left(1+\Delta_{V}\right) ; \text { where } \Delta_{V}=\Delta_{S}^{V}+\Delta_{C}+\Delta_{A} .
\end{aligned}
$$

Finally, as the mass flux through the exhaust fans is computed from pressure and temperature measurements, its uncertainty could be computed as:

$$
\dot{m}=\rho Q \Rightarrow \frac{d \dot{m}}{\dot{m}}=\frac{d \rho}{\rho}+\frac{d Q}{Q} \Leftrightarrow \Delta_{\dot{m}}=\Delta_{\rho}+\Delta_{Q} .
$$

The density in can be evaluated from an ideal gas law correlation [54], so its uncertainty is obtained from the expression

$$
\rho=\rho_{a} \frac{T}{T_{a}} \Rightarrow \frac{d \rho}{\rho}=\frac{d T}{T}-\frac{d T_{a}}{T_{a}} \Leftrightarrow \Delta_{\rho}=\Delta_{T}-\Delta_{T a},
$$

where " $\mathrm{a}$ " refers to ambient conditions. For this calculation an ambient air density of $1.2 \mathrm{Kg} / \mathrm{m}^{3}$ has been assumed.

The volume flow through the exhaust fans is obtained directly from the curve of the fans, see figure 19. It has been assumed a cero uncertainty at this curve, so

$$
\Delta_{Q}=\Delta_{P}
$$

At the end, the mass flux uncertainty would be computed as,

$$
\Delta_{G}=\Delta_{T}-\Delta_{T a}+\Delta_{P}
$$


Sensors characteristics and uncertainties are detailed next:

- Pt 100: Class B, according to IEC 751, its uncertainty is $\Delta_{S}^{T}= \pm 0.1 \%$.

- Thermocouples K: Class 2, according to IEC 584 its uncertainty is $\Delta_{S}^{T}= \pm 0.75 \%$.

- Differential pressure sensor: Its uncertainty is $\Delta_{S}^{P}= \pm 5 \%$.

- Anemometer: its uncertainty is $\Delta_{S}^{V}= \pm 2 \%$.

- Converters: SEM1000 with an uncertainty of $\Delta_{C}= \pm 0.05 \%$.

- PLC: Modules TSX AEY 1600, with an uncertainty of $\Delta_{A}= \pm 0.16 \%$.

Finally, the total uncertainty referred to the $95 \%$ confidence interval ( $k=2$ ) can be obtained according to the ISO standard "Guide to the Expression of Uncertainty in Measurement" [55],

$$
\begin{aligned}
& U_{T_{-} \text {Thermocouples }}=k \sqrt{\left(\Delta_{S}^{T}\right)^{2}+\left(\Delta_{C}\right)^{2}+\left(\Delta_{A}\right)^{2}}=1.54 \%, \\
& U_{T_{-} P t 100}=k \sqrt{\left(\Delta_{S}^{T}\right)^{2}+\left(\Delta_{C}\right)^{2}+\left(\Delta_{A}\right)^{2}}=0.39 \%, \\
& U_{V}=k \sqrt{\left(\Delta_{S}^{V}\right)^{2}+\left(\Delta_{C}\right)^{2}+\left(\Delta_{A}\right)^{2}}=4.02 \%, \\
& U_{\dot{m}}=k \sqrt{2\left(\Delta_{S}^{T}\right)^{2}+2\left(\Delta_{C}\right)^{2}+2\left(\Delta_{A}\right)^{2}+\left(\Delta_{S}^{P}\right)^{2}+\left(\Delta_{C}\right)^{2}+\left(\Delta_{A}\right)^{2}}=10.02 \% .
\end{aligned}
$$

The maximum uncertainty of a measure is obtained at the computation of the mass flux through the exhaust fans due to the relatively high uncertainty of the pressure sensors and the necessity of obtaining this value indirectly. 
Appendix B: Temperatures obtained at the experiment.

In the following tables the temperature values for the quasi-steady state at different parts of the "Atrium" are showed. 


\section{References:}

[1] Tieszen S.R. On the Fluid Mechanics of Fires. Annu. Rev. Fluid Mech. 2001; 33: 67:92.

[2] Chow WK. A preliminary discussion on engineering performance-based codes in the Hong Kong special administrative region. International Journal on Engineering Performance-Based Fire Codes 1999; $1(1): 1-10$.

[3] SFPE engineering guide to performance-based fire protection analysis and design of buildings. Bethesda, Maryland, USA: Society of Fire Protection Engineers; 2001.

[4] BS 7974 Application of fire safety engineering principles to the design of buildings-code of practice. UK: British Standards Institute; 2001.

[5] Wang L, Haworth D.C., Turns S.R., Modest M.F. Interactions among soot, thermal radiation, and NOx emissions in oxygen-enriched turbulent non-premixed flames: a computational fluid dynamics modelling study. Combustion and Flame 2005; 141: $170-179$.

[6] S.R. Tieszen, T.J. O’Hern, R.W. Schefer, E.J. Weckman, T.K. Blancha. Experimental study of the flow field in and around a one meter diameter methane fire. Combust and Flame 2002; 129: 378-391. [7] Lo S.M., Lam K.C. and Yuen K.K., 2000, Views of building surveyors and building services engineers on priority setting of fire safety attributes for building maintenance, Facilities, 18(13/14), 513523.

[8] Yamana T, Tanaka T. Smoke control in large scale spaces. Part 2: smoke control experiments in a large scale space. Fire Sci Technol 1985; (1): 41-54.

[9] Chow WK, Leung W M. Fire-induced convective flow inside an enclosure before flashover: Numerical experiments. Building Services Engineering, Research \& Technology (BSERT) 1989; 10 (2): $51-59$

[10] Chow W K. Application of Computational Fluid Dynamics in building services engineering. Building and Environment 1996; 31 (5): 425-436.

[11] Chow WK. Numerical studies on recent large high-rise building fire. Journal of Architectural Engineering 1998; 4 (2): 65-74.

[12] Chow WK, Cui E, Li YZ, Huo R, Zhou JJ. Experimental studies on natural smoke filling in atria. Journal of Fire Science 2000; 18 (2): 85-103. 
[13] Lu, WZ, Lo, SM, Fang, Z, Yuen, KK, 2001, A preliminary investigation of airflow field in designated refuge floor, Building \& Environment, 36(2), 219-230.

[14] Lu, WZ, Lo, SM, Yuen, KK, Fang, Z, 2001, An investigation of the impact of floor setting on airflow and smoke extraction in designated refuge floor, International Journal of Computational Fluid Dynamics, 14, 327-337.

[15] Cui E, Chow WK. Simulation on indoor aerodynamic induced by an atrium fire. Building and Environment 2005; 40: 1194-1206.

[16] He Y, Wang J, Wu Z, Hu L, Xiong Y, Fan W. Smoke venting and fire safety in an industrial warehouse. Fire Safety Journal 2002; 37: 191-215.

[17] Qin TX, Guo YC, Chan CK, Lin WY. Numerical investigation of smoke exhaust mechanism in a gymnasium under fire scenarios. Building and Environment 2006; 41 (9): 1203-1213.

[18] Jianguo C, Haixin C, Song F. Numerical Investigation of Fire Smoke Transport in the Tsinghua University Sports Center. Tsinghua Science and Technology 2005; 10 (5): 618-622.

[19] Ding W, Minegishi Y, Hasemi Y, Yamada T. Smoke control based on a solar-assisted natural ventilation. Building and Environment 2004; 39 (7): 775-782.

[20] Chow WK, Chow CL. Evacuation with smoke control for atria in green and sustainable buildings. Building and Environment 2005; 40 (2): 195-200.

[21] Fang J, Jie J, Hong-Yong Y, Yong-Ming Z. Early fire smoke movements and detection in high large volume spaces. Building and Environment, In press.

[22] Huo R, Li Y Z. Studies of smoke filling process in large spaces. Journal of Combustion Science and Technology 2001, 7(3): 219-222.

[23] Chow W.K., Li Y.Z., Cui E., Huo R. Natural smoke filling in atrium with liquid pool fires up to 1.6 MW. Building and Environment 2001, 36 (2):121-128

[24] Chow W.K., Cui E., Li Y.Z., Huo R., Zhou J.J. Experimental studies on natural smoke filling atrium. Journal of Fire Sciences 2000, 18 (2): 84 - 103.

[25] Shi, CL, Lu, WZ, Chow, WK, Huo, R, 2007, An investigation on spill plume development and natural filling in large-scale atrium under retail shop fire, Int. J. of Heat \& Mass Transfer, 50, 513-529. 
[26] E. Planas, H. Montiel, J. Casal. A survey of the origin, type and consequences of fire accidents in process plants and in the transportation of hazardous materials. Process Safety and Environmental Protection, Trans. IchemE 1997; 75 (B): 3-8.

[27] Barth TJ, Jespersen D. The design and application of upwind schemes on unstructured meshes. Technical Report AIAA-89-0366, AIAA 27th Aerospace Sciences Meeting, Reno, Nevada, 1989. [28] Patankar SV, Spalding DB. A Calculation Procedure for Heat, Mass and Momentum Transfer in Three-dimensional Parabolic Flows. International Journal for Heat and Mass Transfer 1972; 15: 17871806.

[29] Patankar SV. Numerical Heat Transfer and Fluid Flow, Hemisphere Publishing Corporation, Taylor \& Francis Group, New York, 1980.

[30] Launder BE, Spalding DB. Lectures in Mathematical Models of Turbulence. Academic Press, London, England, 1972.

[31] Cox G. Combustion fundamental of fires. New York: Academic Press; 1995.

[32] Chow WK. Comparison of the use of fire zone and field models for simulating atrium smoke-filling processes. Fire Safety Journal 1995; 25(4): 337-53.

[33] Sinai YL, Owens MP. Validation of CFD modelling of unconfined pool fires with cross-wind flame geometry. Fire Safety Journal 1995; 24: 1-34.

[34] Chow WK, Mok WK. CFD Fire Simulations with Four Turbulence Models and Their Combinations, Journal of Fire Sciences 1999; 17: 209-239.

[35] Bilger RW. Computational field models in fire research and engineering. Fire Safety ScienceProceedings of the Forth International Symposium, International Association for Fire Safety Science, Ottawa, Ontario, Canada, 1994: 95-110.

[36] Chow WK. Use of computational fluid dynamics for simulating enclosure fires. Journal of Fire Sciences 1995; 13(4): 300-34.

[37] Cheng P. Two-Dimensional Radiating Gas Flow by a Moment Method. AIAA Journal 1964; 2:16621664.

[38] Siegel R, Howel JR. Thermal Radiation Heat Transfer. Hemisphere Publishing Corporation, Washington D.C., 1992. 
[39] Gosman AD, Lockwood FC. Incorporation of a flux model for radiation into a finite difference procedure for furnace calculations. 14th Symposium (International) on Combustion. The Combustion Institute Pittsburg 1973; p: 661.

[40] Mustafa I. The effect of thermal radiation and radiation models on hydrogen-hydrocarbon combustion modelling. International Journal of Hydrogen Energy 2005; 30 (10): 1113-1126.

[41] Rigas F, Sklavounos S. Simulation of Coyote series trials - Part II: A computational approach to ignition and combustion of flammable vapour clouds. Chemical Engineering Science, March 2006; 61: 1444-1452.

[42] Fluent 6.2 User's Guide.

[43] Beyler, C.L. The SFPE Hanbook for Fire Safety Engineering, Section two, Chapter 2-7, $3^{\text {rd }}$ Ed. NFPA, Quincy, Massachusetts International.

[44] Fay, J.A. Model of large pool fires. Journal of Hazardous Materials. 2006; 136 (21): 219-232.

[45] Koseki H, Yumoto T. Air entrainment and thermal radiation from heptane pool fires. Fire Technology 1988; 24: 33-47.

[46] Thomas PH. Ninth Symposium (International) on Combustion, Academic Press, New York, 1963, pp: 844-859.

[47] Kim MB, Jang YJ, Kim JK. Burning rate of a pool fire with downward-directed sprays. Fire Safety Journal 1996; 27: 37-48.

[48] Quintiere JG. Principles of fire behaviour. Delmar Publishers, New York, 1997.

[49] Jovaní Sales M. Fundamentals on Radiation of Combustion Products. Polytechnic University of Valencia, 1994.

[50] Eaton, A.M., Smoot, L.D., Hill, S.C., Eatough, C.N.. Components, formulations, solutions, evaluation, and application of comprehensive combustion models. Progress in Energy and Combustion Science 25 (1999) 387-436

[51] Cuoci, A., Frassoldati, A., Buzzi Ferraris, G., Faravelli, T., Ranzi E. The ignition, combustion and flame structure of carbon monoxide/hydrogen mixtures. Note 2: Fluid dynamics and kinetic aspects of syngas combustion. International Journal of Hydrogen Energy, In press.

[52] Burke, S.P., Schumann, T.E.W. Diffusion flames. Industrial and Engineering Chemistry, 1928; 20, 998-1024. 
[53] NFPA 92B. Guide of smoke management systems in atria, covered malls, and large areas. National Protection Association, Quincy, MA, USA, 1995.

[54] ISO “Guide to the Expression of Uncertainty in Measurement”, Corrected and rep. 1995,

International Organization for Stand. (ISO), Geneva, Switzerland, pp. 9-78.

[55] Drysdale DD. An introduction to fire dynamics. 2000. John Wiley \& Sons Ltd, Chichester. 


\section{Figure Captions.}

Figure 1. "Fire Atrium" of the Technological Metal Centre, in Murcia, Spain.

Figure 2. Fire Atrium scheme.

Figure 3. Wall A sensors layout: a) air temperature close to wall, b) wall temperature.

Figure 4. As in figure 3, but at wall C. View from the inside.

Figure 5. Central section seen from wall A (a), and roof sensors' layout (b). Absolute pressure (A.P.), differential pressure (D.P.) and temperature (T).

Figure 6. Detail of the scaled residuals of a converged case for the "simulation 2".

Figure 7. 'Fire atrium' meshing: a) general mesh, and b) detail of the zone next to exhaust fans.

Figure 8. Thermal source shape and dimensions.

Figure 9. Fuel injection scheme for "simulation 2".

Figure 10. Hearth and fire for the case studied.

Figure 11. Heat release rate of fire source.

Figure 12. Transient temperature in atrium measured with sensor 60, sensor 25 and sensor 3, in a), and sensor 59, sensor 12 and sensor 15 , in b) .

Figure 13. Temperature contour lines on the roof and for the hot flow through the exhaust fans. Twenty equidistant isocontours are plotted in the interval $[317.65 \mathrm{~K}, 351.15 \mathrm{~K}]$ for the "simulation 1 " in a), and [316.30 K, $359.53 \mathrm{~K}]$ for "simulation 2" in b).

Figure 14. Comparison between experimental and numerical wall temperature results at wall C, seen from the inside. Twenty equidistant isocontours are plotted in the interval [291.55 K, $320.75 \mathrm{~K}$ ] for the “simulation 1" in a), and [301.58 K, 328.33 K] for the "simulation 2" in b).

Figure 15. Comparison between experimental and numerical air temperature results close to the wall C, seen from the inside. Twenty equidistant isocontours are plotted in the interval [290.15 K, $343.65 \mathrm{~K}]$ for the "simulation 1" in a), and [294.01 K, 348,02 K] for the "simulation 2" in b).

Figure 16. Comparison between experimental and numerical air temperature results at the central section $(y=9.75 \mathrm{~m})$. Twenty equidistant isocontours are plotted in the interval $[293.15 \mathrm{~K}, 423.15 \mathrm{~K}]$ for the "simulation 1" in a), and [300.02 K, $632.08 \mathrm{~K}]$ ] for the "simulation 2" in b). View from the wall A. 
Figure 17. Contour lines of the air velocity flow field, $|\vec{v}|$ at the central section $(\mathrm{y}=9.75 \mathrm{~m})$. Twenty equidistant isocontours are plotted in the interval $[0 \mathrm{~m} / \mathrm{s}, 13.8 \mathrm{~m} / \mathrm{s}]]$ for the "simulation 1 " in a), and $[0$ $\mathrm{m} / \mathrm{s}, 15.0 \mathrm{~m} / \mathrm{s}$ ] ] for the "simulation 2" in b). View from wall A.

Figure 18. Contour lines of the air normal velocity $\left(v_{y}\right)$ to the vent A1. Continuous lines correspond to inwards (positive) flow and dashed lines to outwards (negative) values. Twenty equidistant isocontours are plotted in the interval $[-0.61 \mathrm{~m} / \mathrm{s}, 0.66 \mathrm{~m} / \mathrm{s}]$ ] for the "simulation 1 " in a), and $[-0.77 \mathrm{~m} / \mathrm{s}, 0.57 \mathrm{~m} / \mathrm{s}]$ ] for the "simulation 2 " in b). View from outside.

Figure 19. Exhaust fans operating curves (static pressure versus flow). The exhaust fans with diameter equal to $0.56 \mathrm{~m}$ are the installed ones.

Figure 20. Numerical wall $\mathrm{C}$ temperature results, predicted for the alternative exhaust fans: a) $\mathrm{D}=0.8 \mathrm{~m}$, and b) $\mathrm{D}=1 \mathrm{~m}$. Twenty equidistant isocontours are plotted in the following intervals: [296.75 $\mathrm{K}, 315.12$ $\mathrm{K}$ ] for a), and [295.84 K, $310.52 \mathrm{~K}$ ] for b). Wall C seen from the inside.

Figure 21. Contour lines of the vertical air velocity flow field, $v_{z}$, near the roof in a central section, $\mathrm{y}=9.75$ $\mathrm{m}$, for alternative exhaust fans: a) $\mathrm{D}=0.8 \mathrm{~m}$, and b) $\mathrm{D}=1 \mathrm{~m}$. Continuous lines correspond to outward (positive) flow. Dashed lines correspond to inwards (negative) flow. Twenty equidistant isocontours are plotted in the following intervals: $[-0.61 \mathrm{~m} / \mathrm{s}, 5.00 \mathrm{~m} / \mathrm{s}]$ for a), and $[0 \mathrm{~m} / \mathrm{s}, 5.00 \mathrm{~m} / \mathrm{s}]$ for b). View from wall A.

Figure 22. Contour lines of the air normal velocity $\left(v_{y}\right)$ to the vent A1 for the alternative exhaust fans: a) $\mathrm{D}=0.8 \mathrm{~m}$, and b) $\mathrm{D}=1 \mathrm{~m}$. Continuous lines correspond to outward (positive) flow. Dashed lines correspond to inwards (negative) flow. Twenty equidistant isocontours are plotted in the following intervals: $[-0.08 \mathrm{~m} / \mathrm{s}, 0.95 \mathrm{~m} / \mathrm{s}]$, for a), $[0.165 \mathrm{~m} / \mathrm{s}, 1.11 \mathrm{~m} / \mathrm{s}]$, for b). View from outside.

Figure 23. Air temperature in a vertical line located at $x=y=14.625 \mathrm{~m}$, in a), and carbon dioxide mole concentration at the same line, in b).

Figure A1. Scheme of the acquisition data chain. 
Figure 1
Click here to download high resolution image

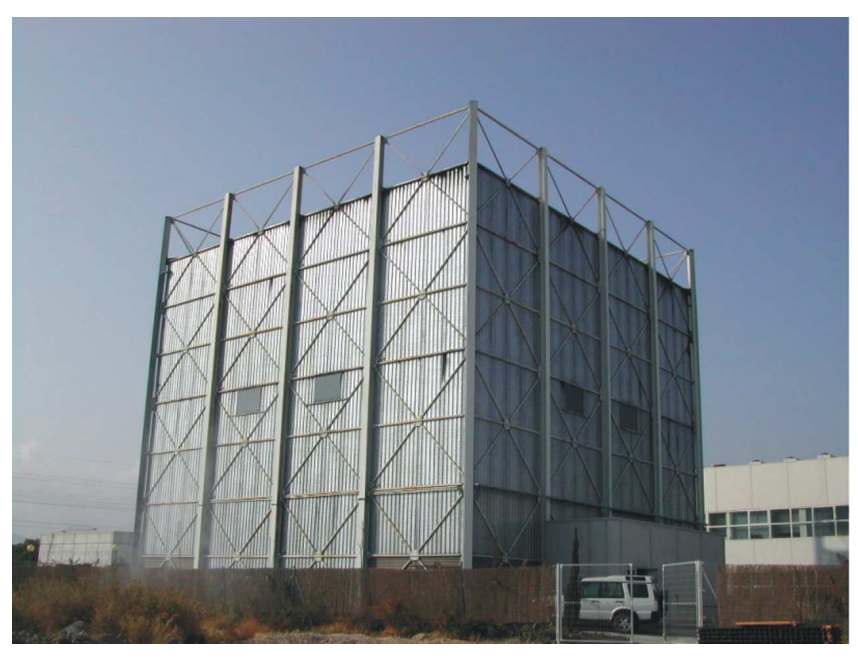




\section{Figure2}

Click here to download high resolution image

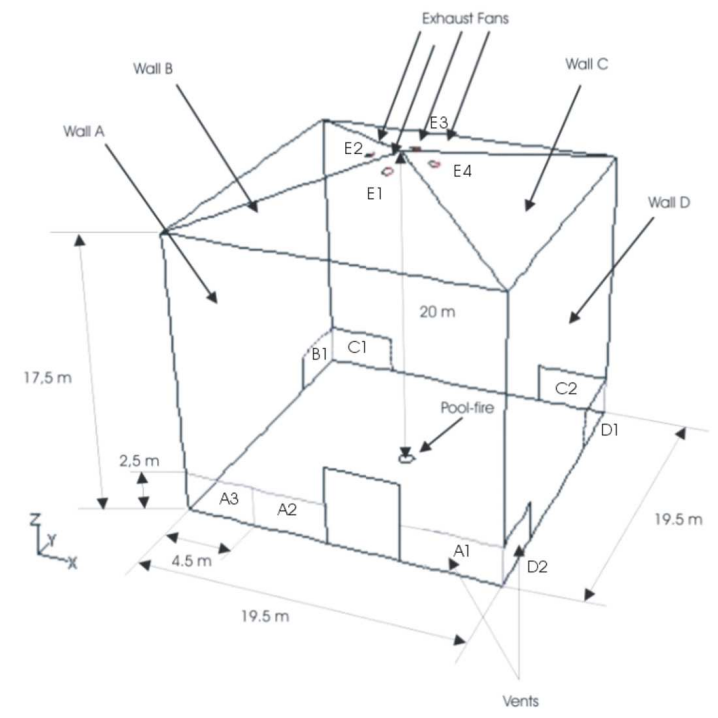




\section{Figure3}

Click here to download high resolution image
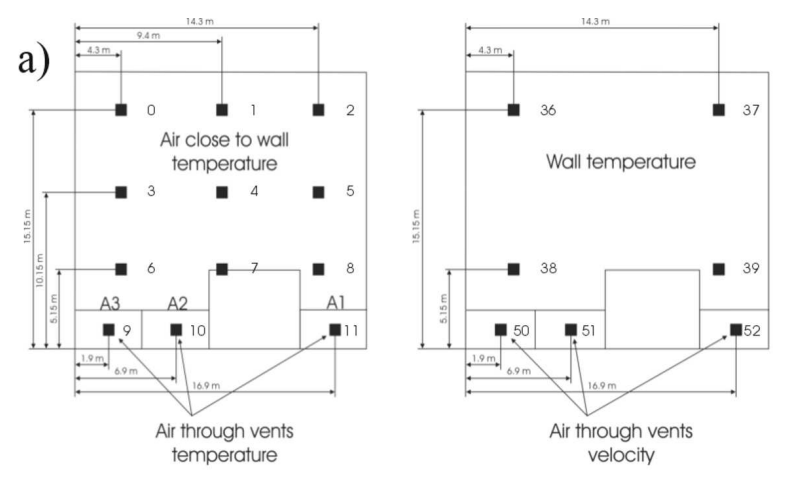

b) 
a)

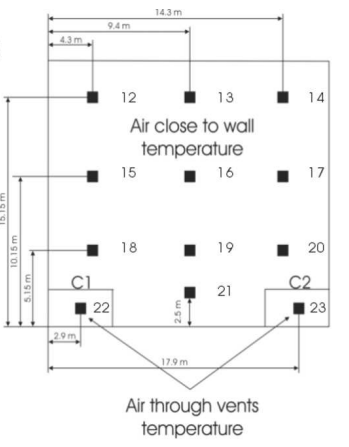

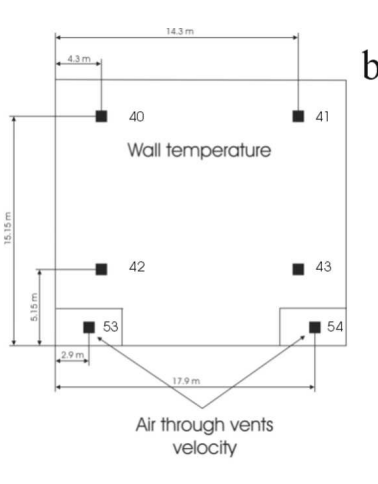

b)

)

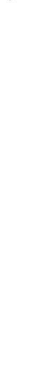

Figure 4
Click here to download high resolution image

Figure 4
Click here to download high resolution image

)

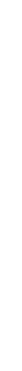

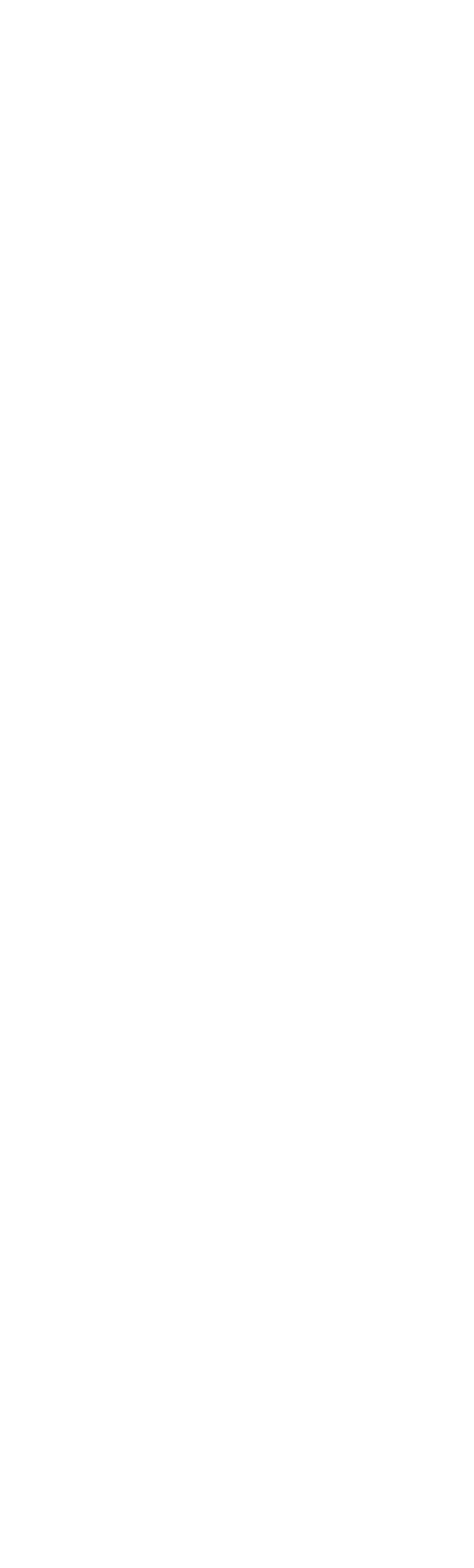


Figure5

Click here to download high resolution image

a)

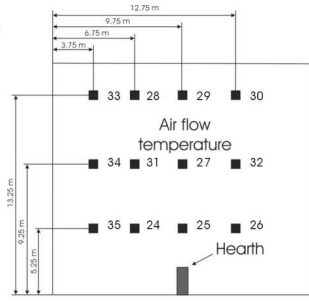

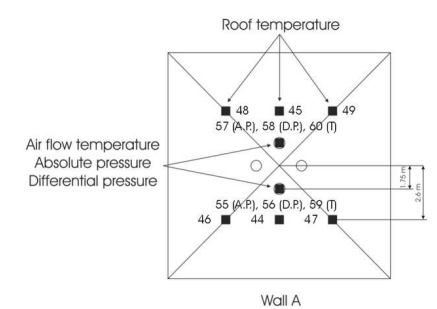




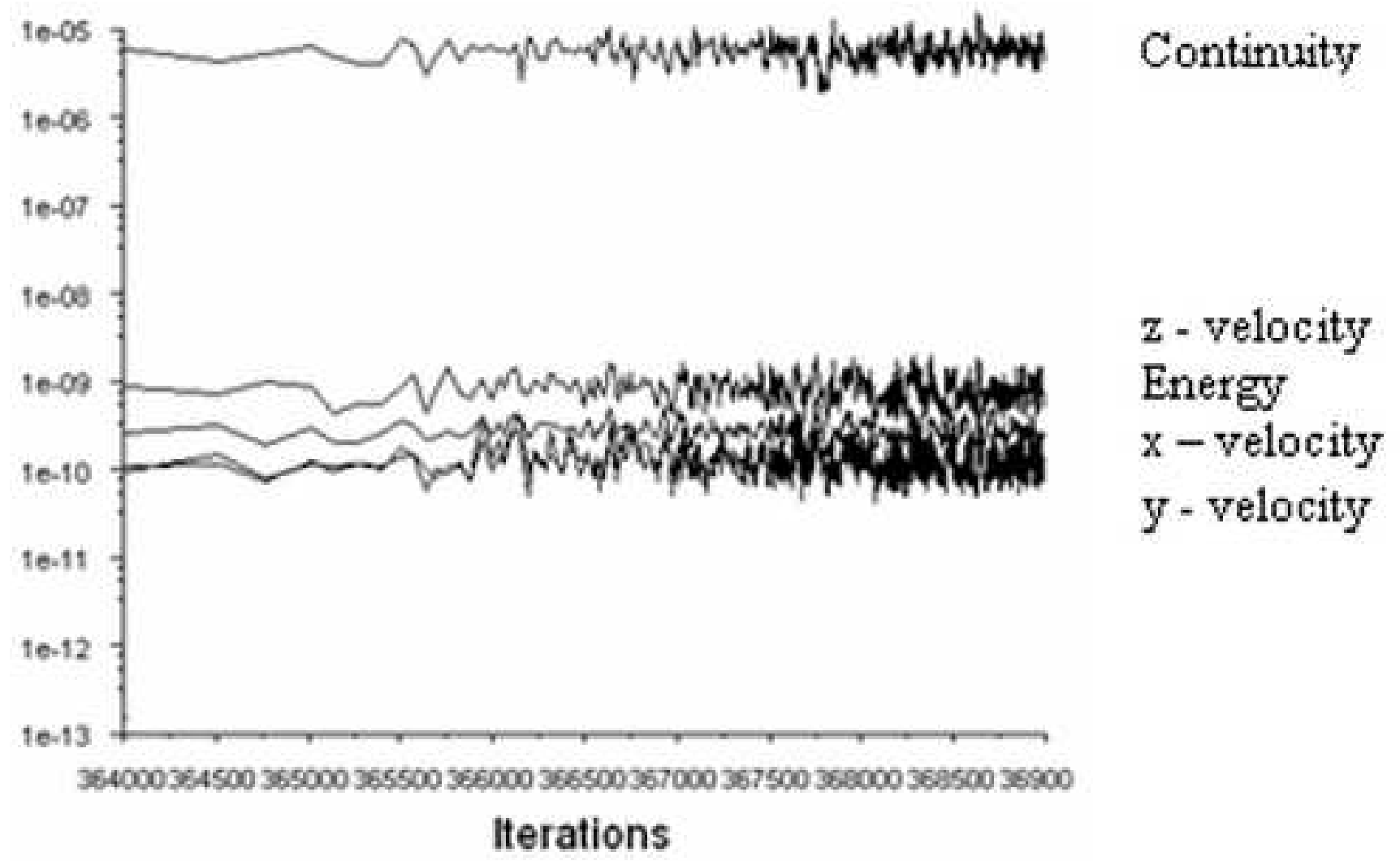


Figure7
Click here to download high resolution image

a)

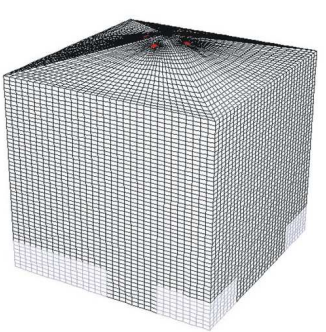

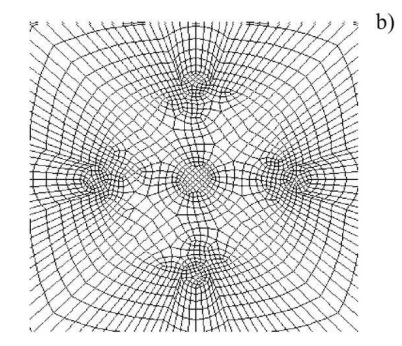

\author{
"
}

. 


\section{Click here to download high resolution image}

D

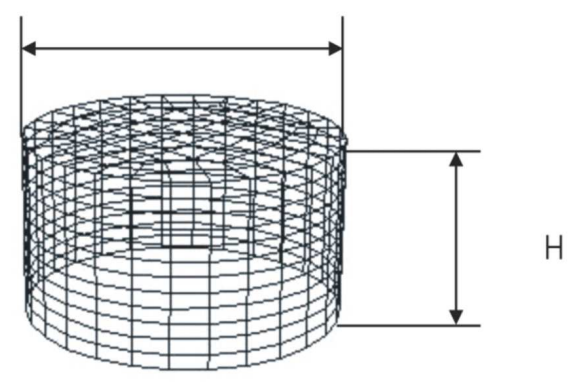




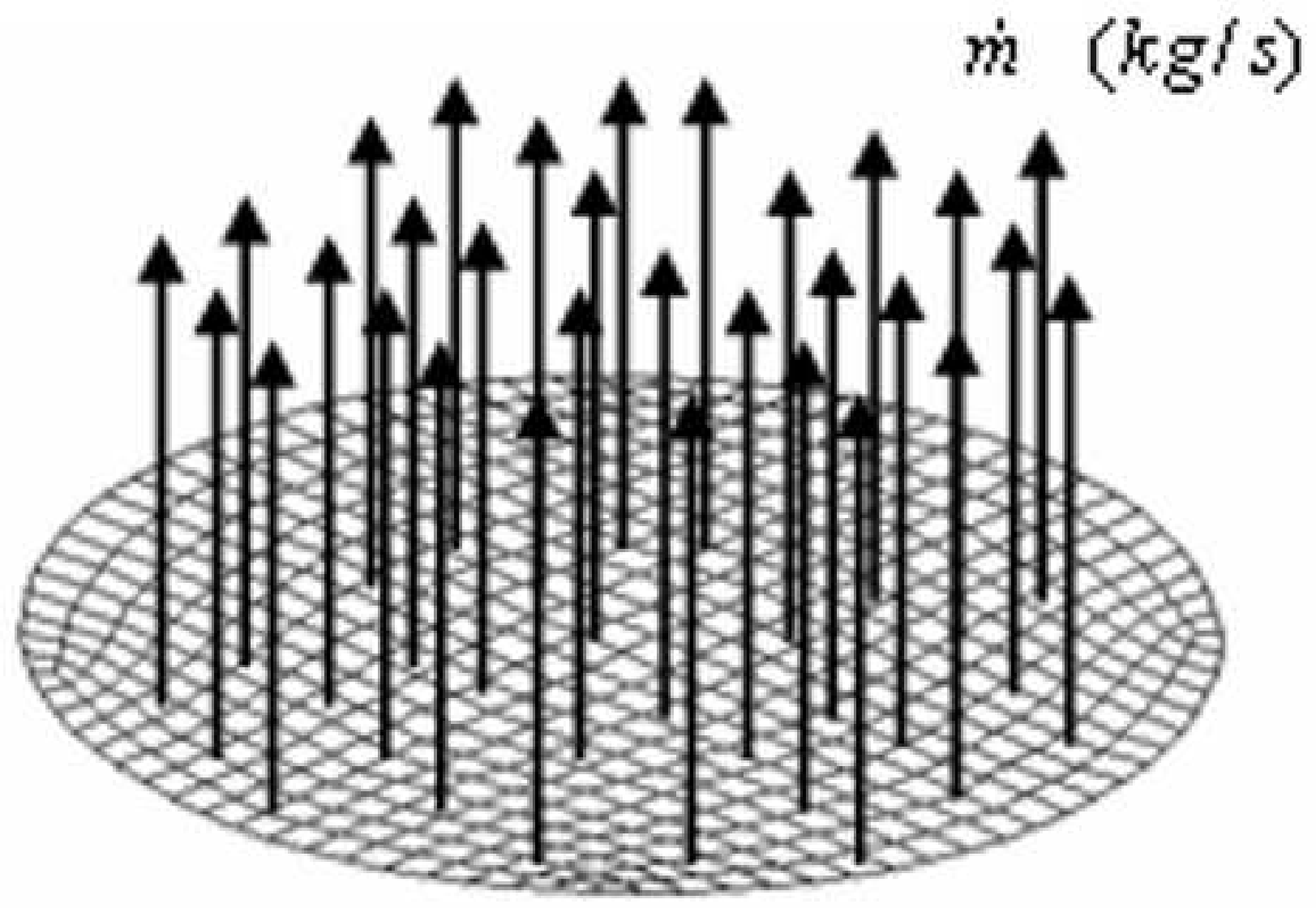


Click here to download high resolution image

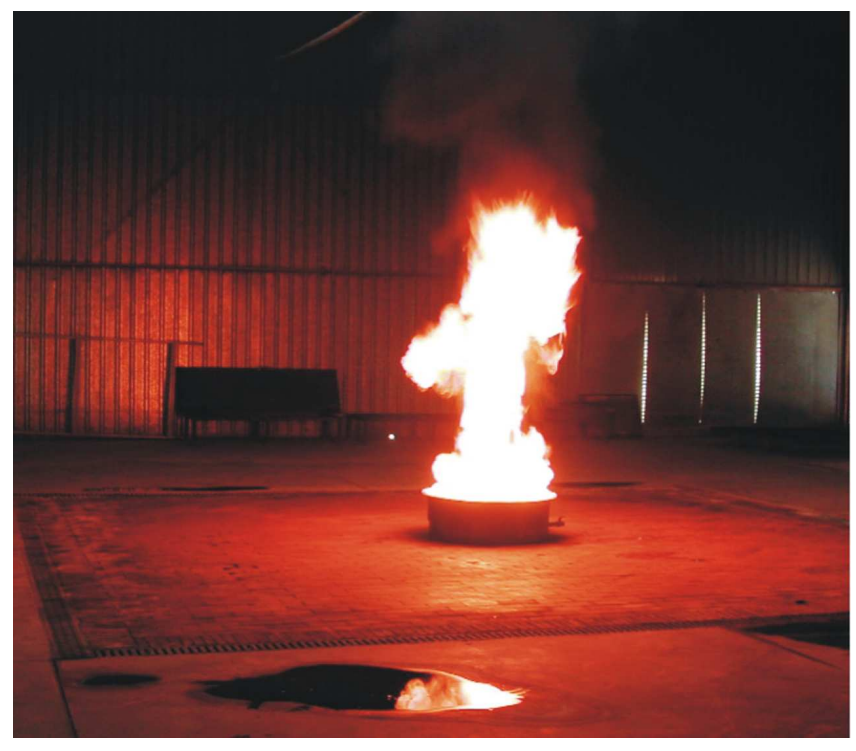


Figure 11
Click here to download high resolution image

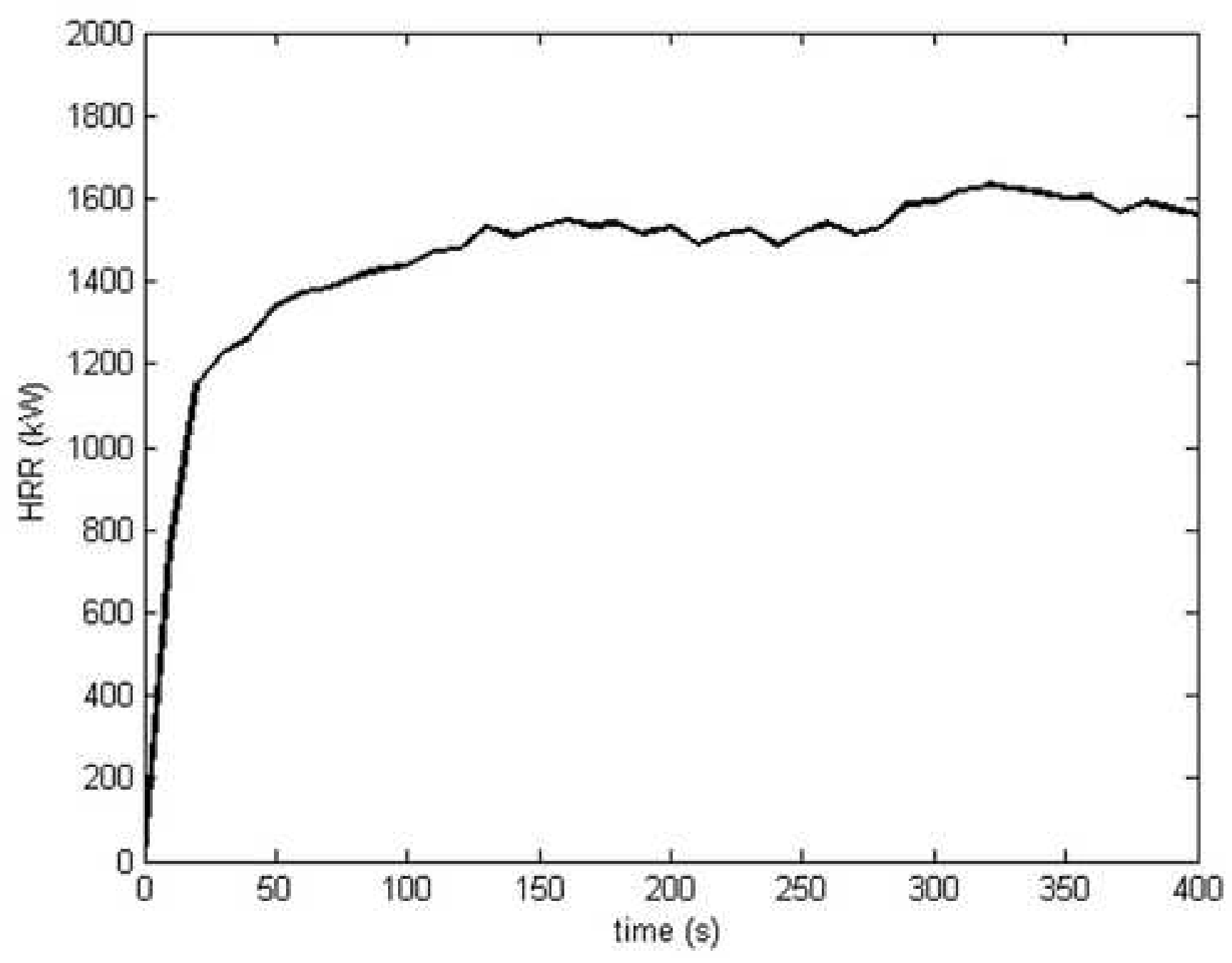


Figure 12
Click here to download high resolution image

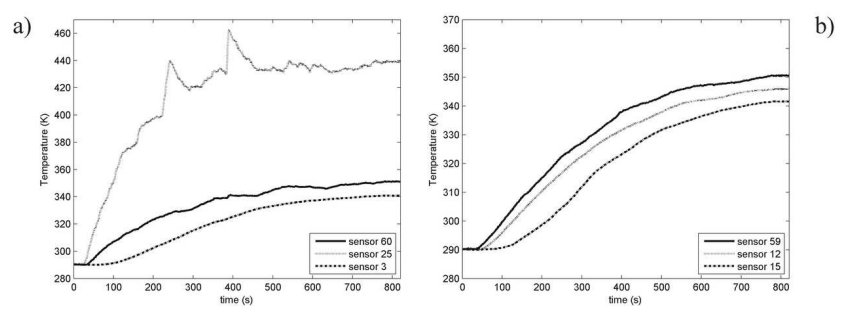

b) 
Figure 13
Click here to download high resolution image

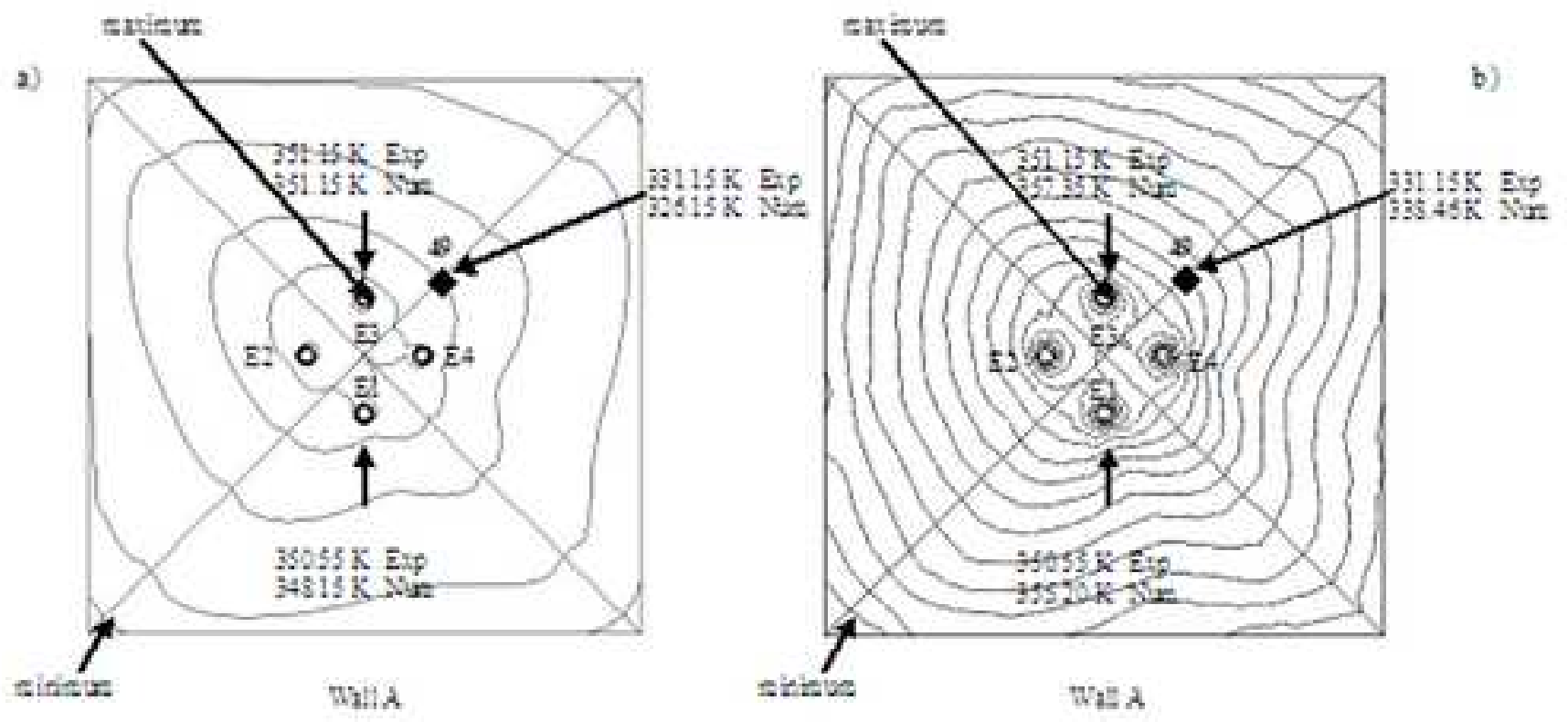

)

stitus wa 
Click here to download high resolution image
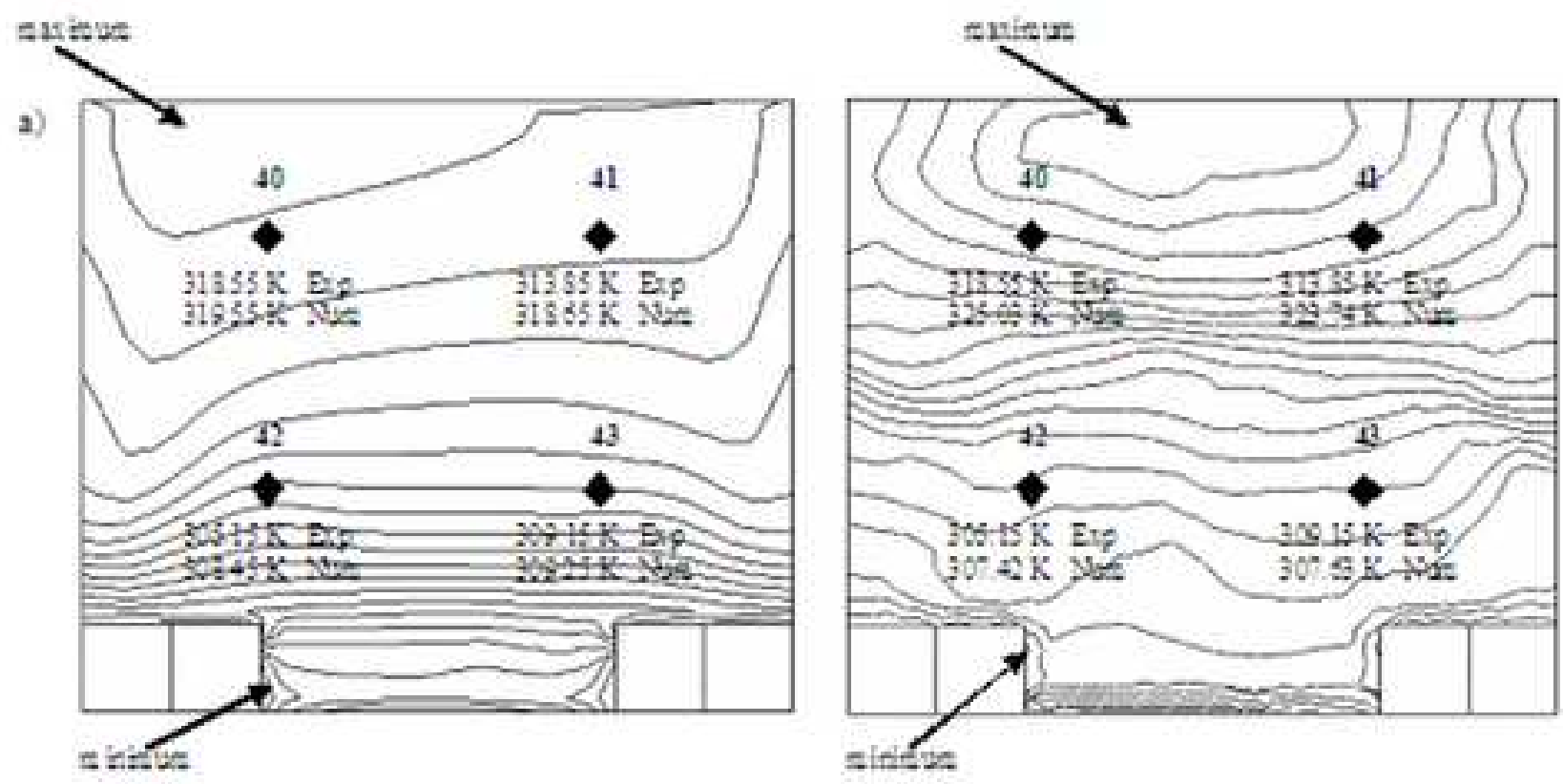

b) 


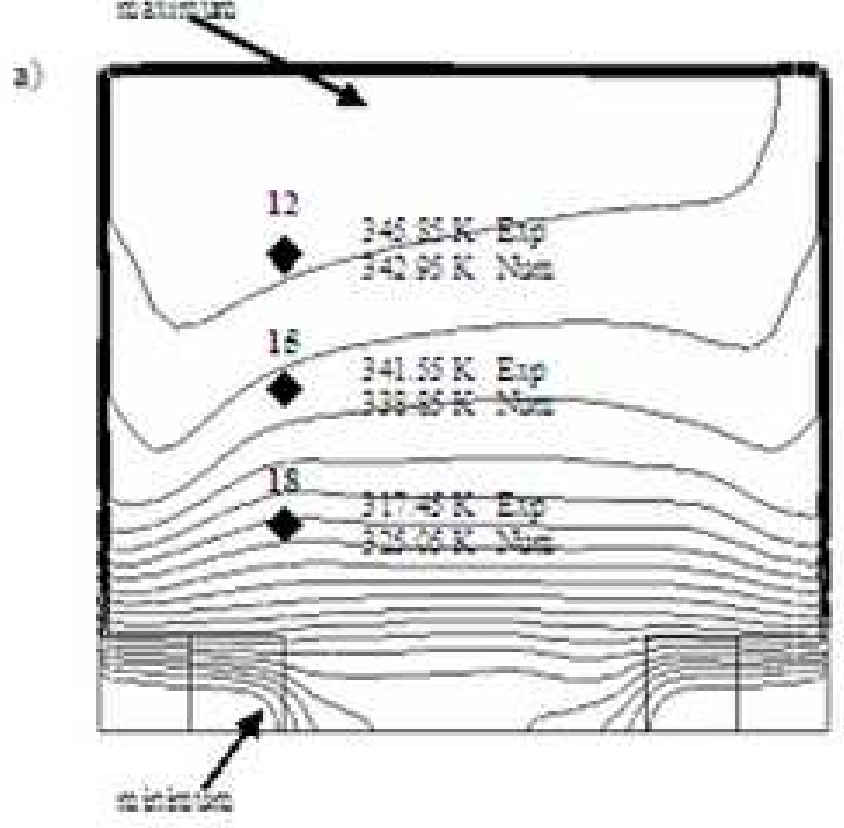

a)

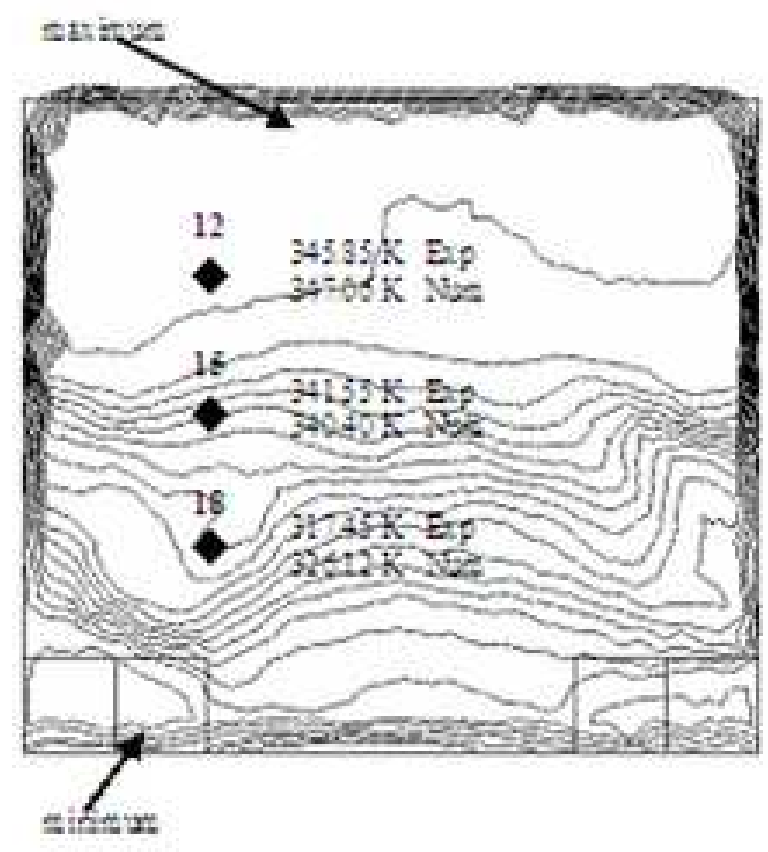

b)
Click here to download high resolution image 
Click here to download high resolution image

a)

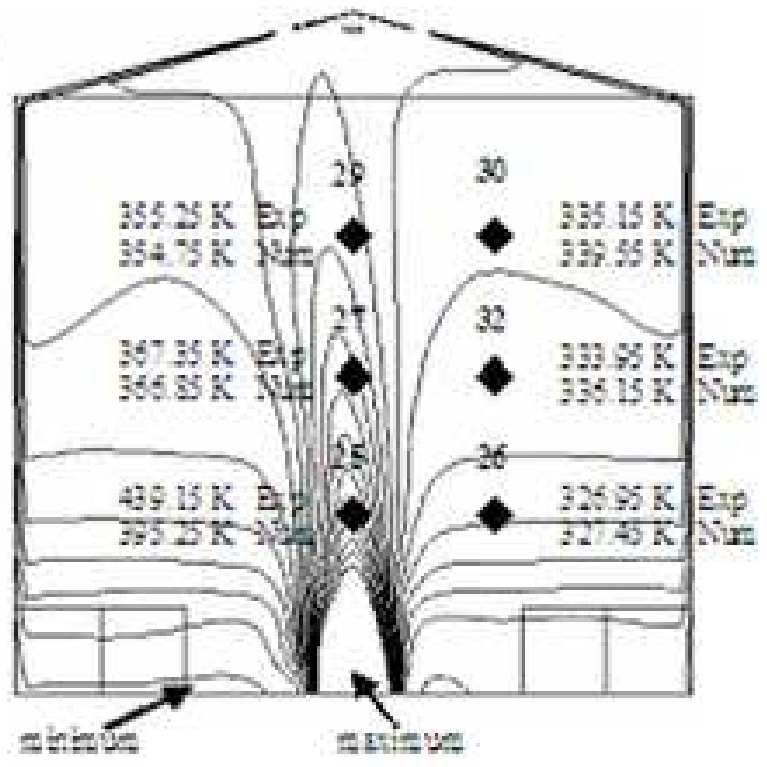

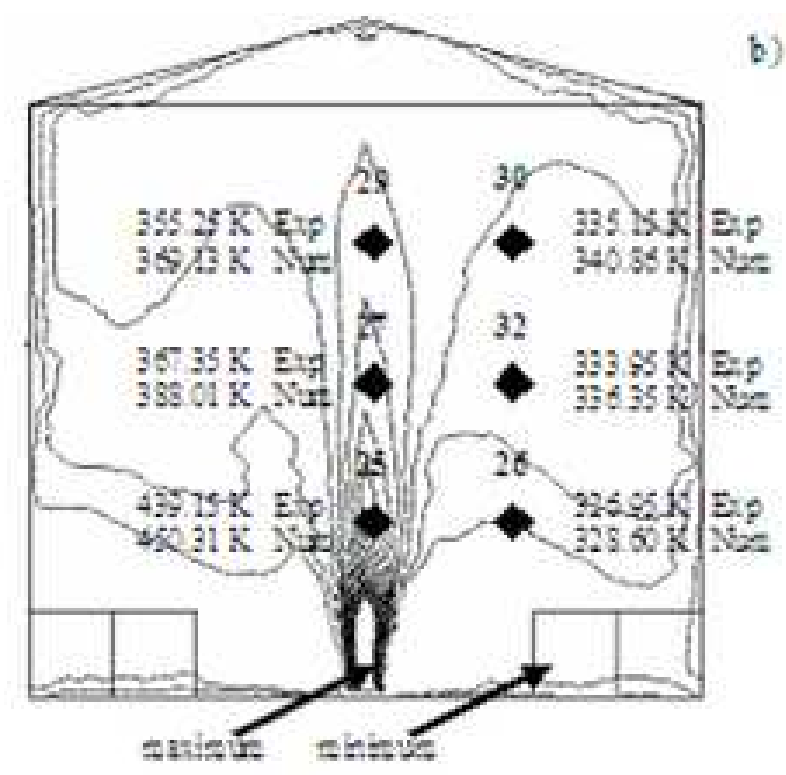

b) 
Figure 17
Click here to download high resolution image
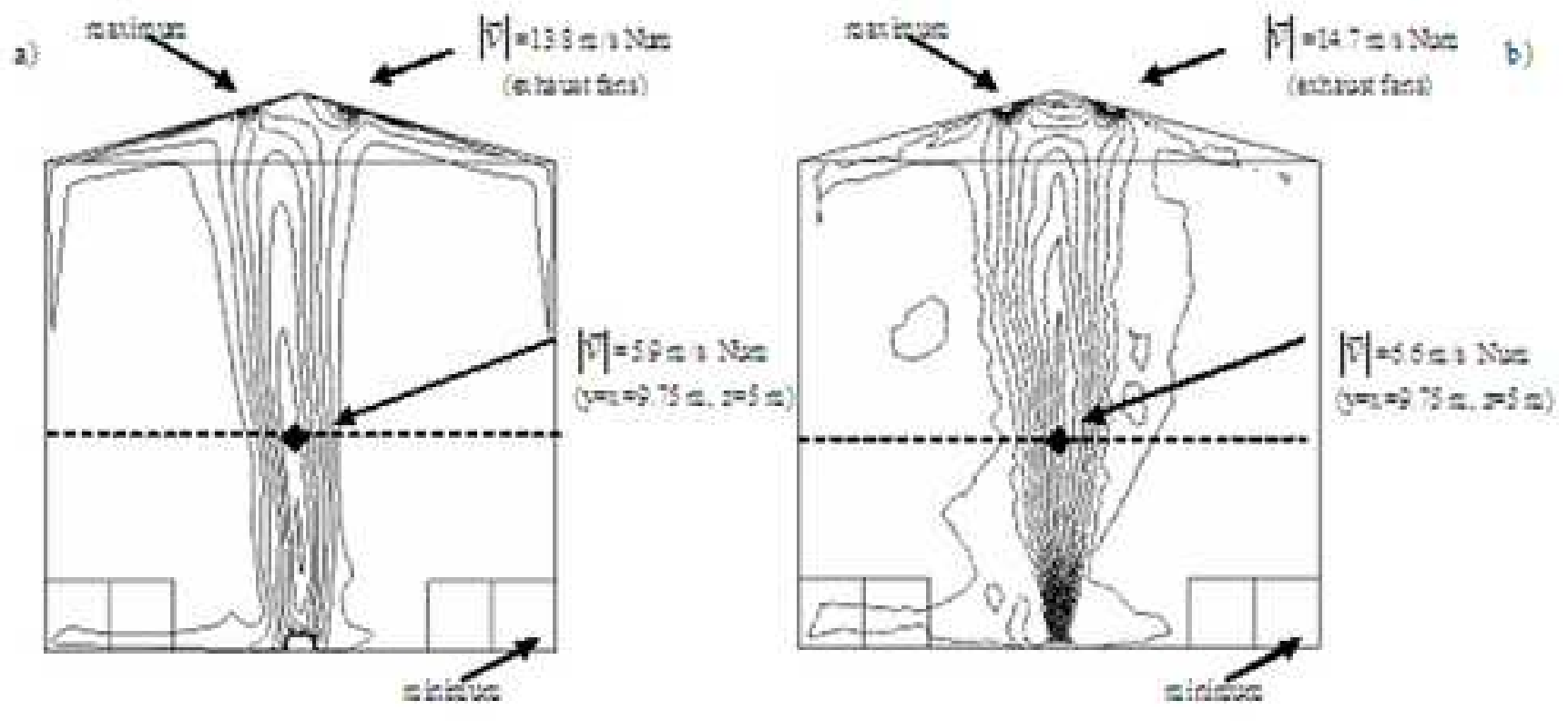
Figure18

Click here to download high resolution image

2)
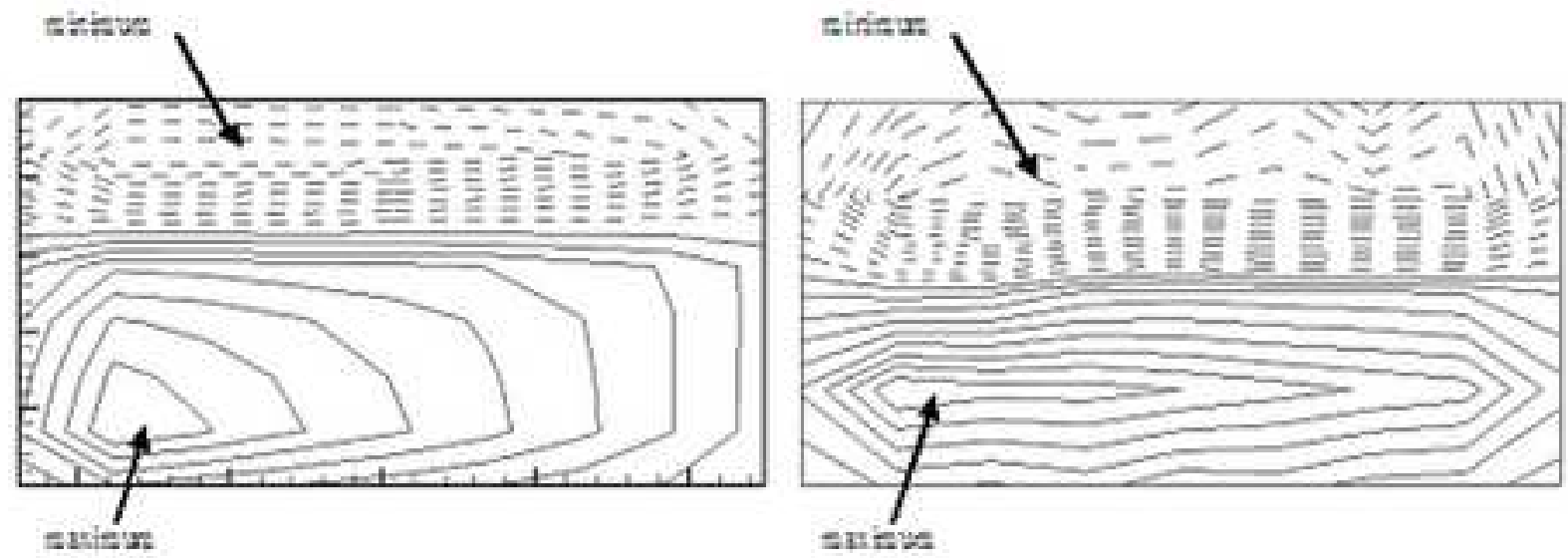
Click here to download high resolution image

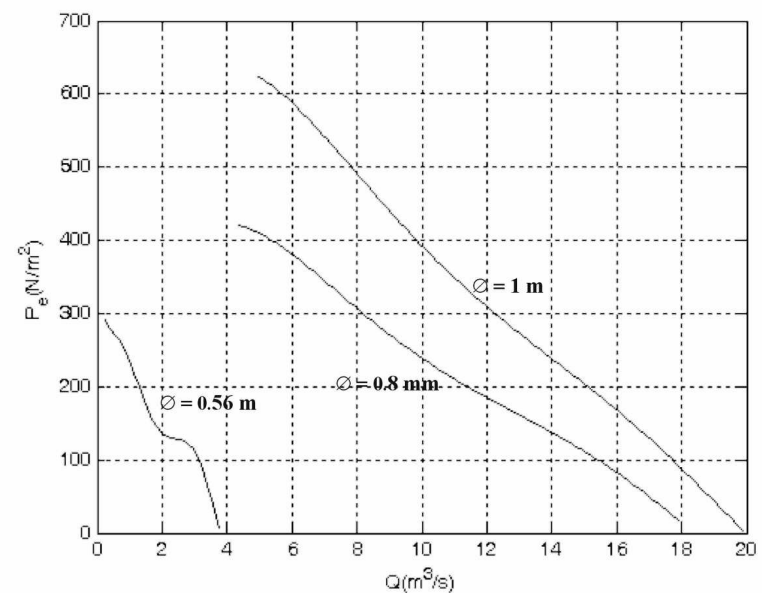


Click here to download high resolution image

a)
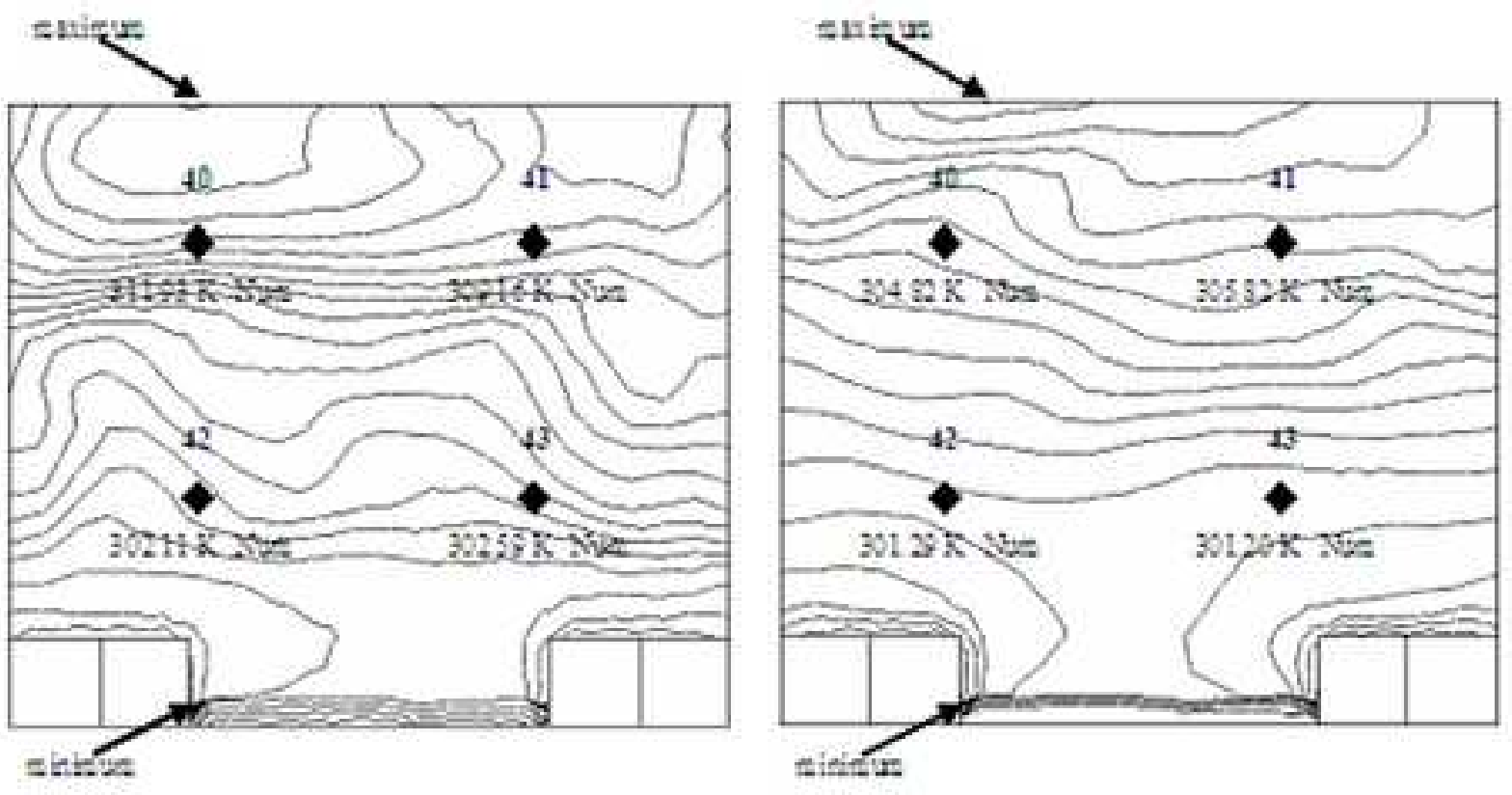

b) 


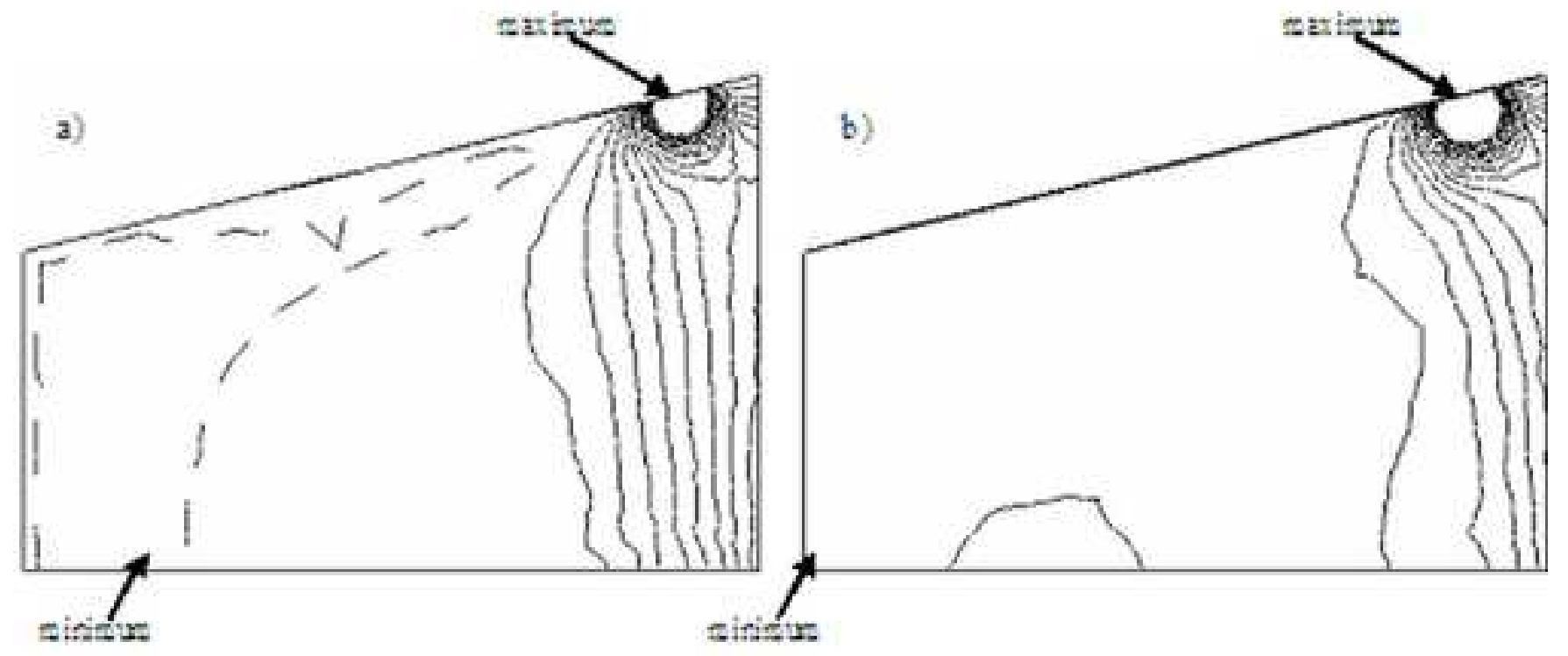


Click here to download high resolution image

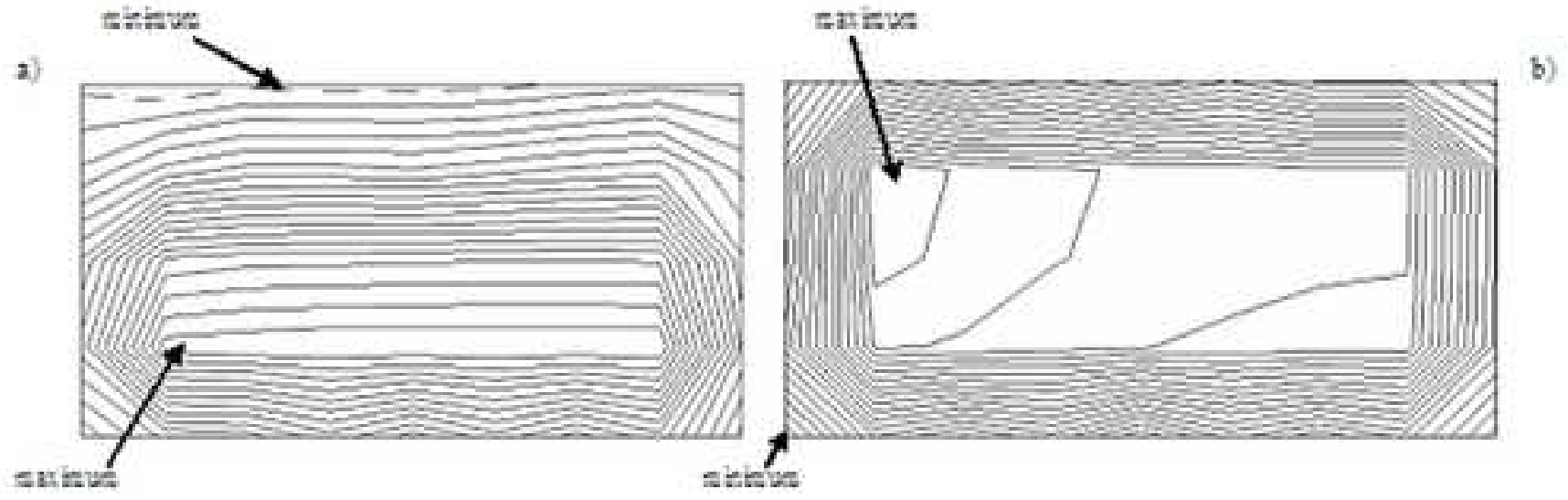

b) 
a)

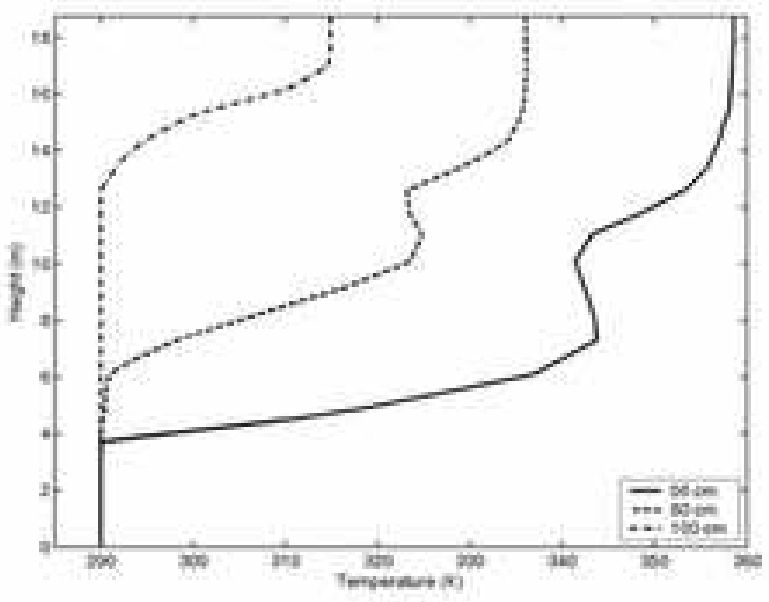

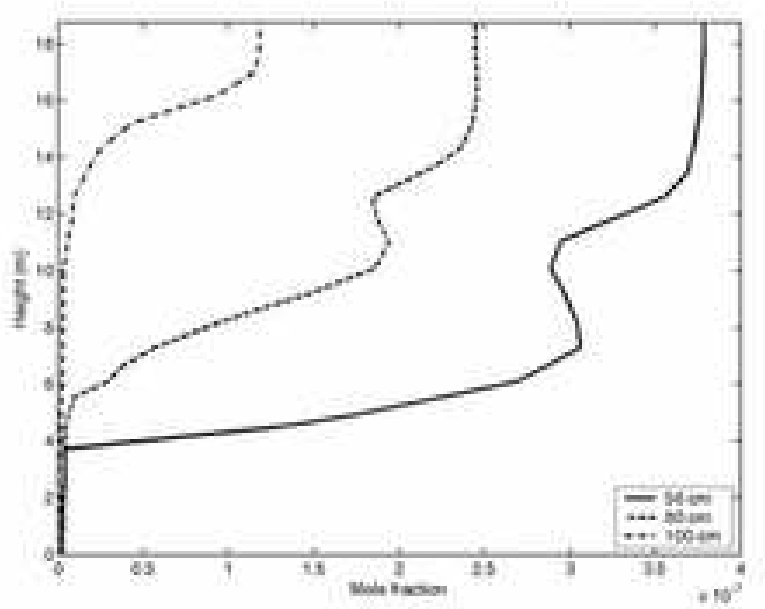

b) 
FigureA1

Click here to download high resolution image

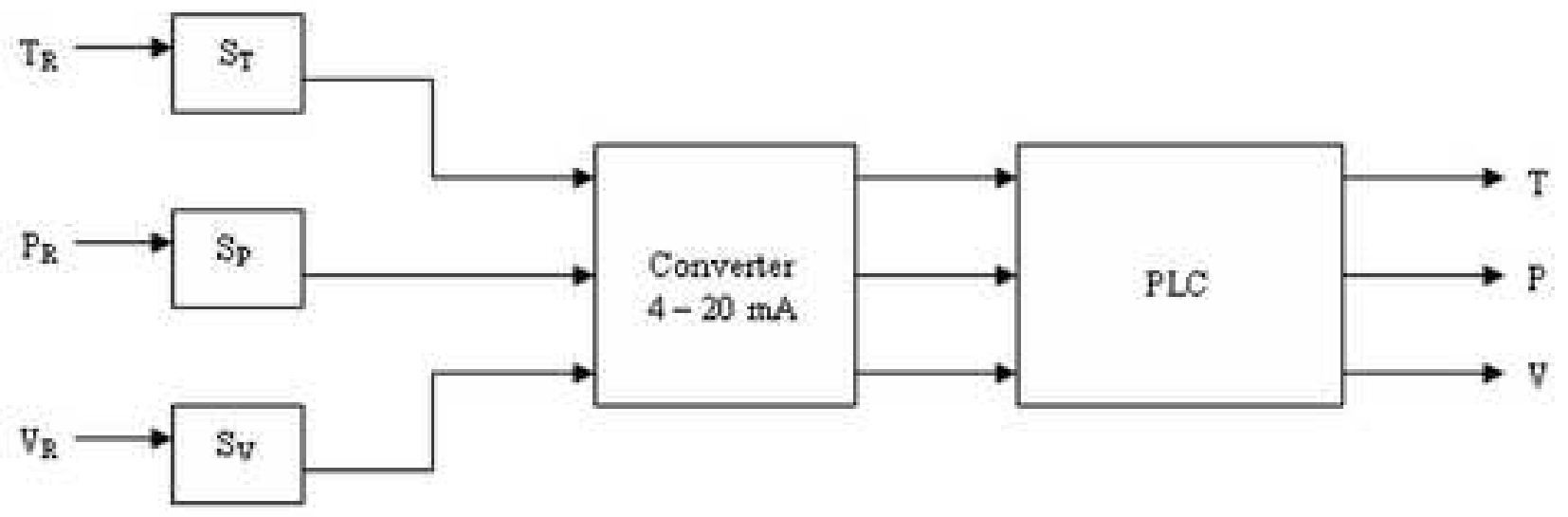


Table 1

Mass and heat transfer rate flow imbalance of a converged case

\begin{tabular}{cccc}
\hline Flows imbalance & Inflow & Outflow & Deviation/Error (\%) \\
\hline Mass (kg/s) & 12.8378 & -12.8253 & 0.0974 \\
Heat transfer rate (kW) & 1585801.3 & -1585319.7 & 0.0303 \\
\hline
\end{tabular}


Table 2

Air flow through the exhaust fans, in $\mathrm{m}^{3} / \mathrm{s}$

\begin{tabular}{cccc}
\hline \multirow{2}{*}{ Exhaust fan } & \multirow{2}{*}{ Experimental measures } & \multicolumn{2}{c}{ Numerical results } \\
\cline { 3 - 4 } & & Simulation 1 & Simulation 2 \\
\hline E1 & 3.7 & 3.2 & 3.6 \\
E2 & Not measured & 3.2 & 3.6 \\
E3 & 3.8 & 3.3 & 3.7 \\
E4 & Not measured & 3.2 & 3.6 \\
\hline
\end{tabular}


Table 3

Comparison between experimental and numerical results for the air through the vents velocity at its middle ground, in $\mathrm{m} / \mathrm{s}$

\begin{tabular}{cccc}
\hline \multirow{2}{*}{ Vent } & \multirow{2}{*}{ Experimental measures } & \multicolumn{2}{c}{ Numerical results } \\
\cline { 3 - 4 } & & Simulation 1 & Simulation 2 \\
\hline A1 & $0.4-0.5$ & 0.33 & 0.35 \\
A2 & $0.4-0.5$ & 0.45 & 0.48 \\
A3 & $0.3-0.45$ & 0.45 & 0.47 \\
C1 & $0.2-0.3$ & 0.28 & 0.30 \\
C2 & $0.1-0.25$ & 0.28 & 0.31 \\
\hline
\end{tabular}


Table 4

Exhaust fans outflow, in $\mathrm{m}^{3} / \mathrm{s}$

\begin{tabular}{lccccc}
\hline & $\begin{array}{c}\text { Experimental } \\
\varnothing=\mathbf{0 . 5 6} \mathbf{~ m}\end{array}$ & $\begin{array}{c}\boldsymbol{\varnothing}=\mathbf{0 . 5 6} \mathbf{~ m} \\
\text { (natural } \\
\text { ventilation) }\end{array}$ & $\boldsymbol{\varnothing}=\mathbf{0 . 5 6} \mathbf{~ m}$ & $\boldsymbol{\varnothing}=\mathbf{0 . 8} \mathbf{~ m}$ & $\boldsymbol{\varnothing}=\mathbf{1 ~ \mathbf { ~ m }}$ \\
\hline Exhaust fan 1 & 3.7 & 1.7 & 3.6 & 7.9 & 14.3 \\
Exhaust fan 2 & - & 1.8 & 3.6 & 8.0 & 14.5 \\
Exhaust fan 3 & 3.8 & 1.9 & 3.7 & 7.8 & 14.6 \\
Exhaust fan 4 & - & 1.6 & 3.6 & 7.8 & 14.4 \\
\hline
\end{tabular}


Table B1

Temperatures at wall $\mathrm{A}$ and wall $\mathrm{C}$,

\begin{tabular}{cccc}
\hline Zone & Height $(\mathbf{m})$ & Sensor & Temperature (K) \\
\hline \multirow{2}{*}{ Wall A } & $\mathbf{1 5 . 1 5}$ & $\mathbf{3 6}$ & 314.95 \\
& & $\mathbf{3 7}$ & 310.65 \\
& $\mathbf{5 . 1 5}$ & $\mathbf{3 8}$ & 309.95 \\
& & $\mathbf{3 9}$ & 305.25 \\
Wall C & $\mathbf{1 5 . 1 5}$ & $\mathbf{4 0}$ & 318.55 \\
& & $\mathbf{4 1}$ & 313.85 \\
& \multirow{5}{*}{$\mathbf{5 . 1 5}$} & $\mathbf{4 2}$ & 305.15 \\
& & $\mathbf{4 3}$ & 309.15 \\
\hline
\end{tabular}


Table B2

Temperatures at the roof,

\begin{tabular}{|c|c|c|c|}
\hline \multicolumn{2}{|c|}{ Zone } & \multirow{2}{*}{$\begin{array}{c}\text { Sensor } \\
46\end{array}$} & \multirow{2}{*}{$\frac{\text { Temperature }(\mathbf{K})}{330.05}$} \\
\hline \multirow{4}{*}{ Near the beams } & \multirow{2}{*}{ Wall A } & & \\
\hline & & 47 & 328.95 \\
\hline & \multirow{2}{*}{ Wall C } & 48 & 332.85 \\
\hline & & 49 & 331.15 \\
\hline \multirow{2}{*}{ Near the fans } & Wall A & 44 & 330.55 \\
\hline & Wall C & 45 & 332.45 \\
\hline
\end{tabular}


Table B3

Air close to wall A and wall $\mathrm{C}$ temperature,

\begin{tabular}{|c|c|c|c|}
\hline Zone & Height (m) & Sensor & Temperature (K) \\
\hline \multirow{11}{*}{ Wall A } & \multirow{3}{*}{15.15} & $\mathbf{0}$ & 344.95 \\
\hline & & 1 & 344.95 \\
\hline & & 2 & 344.75 \\
\hline & \multirow{3}{*}{10.15} & 3 & 340.75 \\
\hline & & 4 & 341.35 \\
\hline & & 5 & 340.95 \\
\hline & \multirow{3}{*}{5.15} & 6 & 320.75 \\
\hline & & 7 & 317.95 \\
\hline & & 8 & 324.15 \\
\hline & \multirow{3}{*}{ Vent } & 9 & 296.25 \\
\hline & & 10 & 297.35 \\
\hline \multirow{12}{*}{ Wall C } & & 11 & 295.45 \\
\hline & \multirow{3}{*}{15.15} & 12 & 345.85 \\
\hline & & 13 & 345.95 \\
\hline & & 14 & 345.65 \\
\hline & \multirow{3}{*}{10.15} & 15 & 341.55 \\
\hline & & 16 & 341.45 \\
\hline & & 17 & 341.45 \\
\hline & \multirow{3}{*}{5.15} & 18 & 317.45 \\
\hline & & 19 & 317.15 \\
\hline & & 20 & 317.15 \\
\hline & \multirow{2}{*}{ Vent } & 22 & 298.35 \\
\hline & & 23 & 298.85 \\
\hline
\end{tabular}


Table B4

Air temperature at the central section,

\begin{tabular}{cccc}
\hline Zone & Height $(\mathbf{m})$ & Sensor & Temperature (K) \\
\hline \multirow{3}{*}{ Plume } & $\mathbf{1 3 . 2 5}$ & $\mathbf{2 9}$ & 355.25 \\
& $\mathbf{9 . 2 5}$ & $\mathbf{2 7}$ & 367.35 \\
& $\mathbf{5 . 2 5}$ & $\mathbf{2 5}$ & 439.15 \\
& & $\mathbf{3 3}$ & 332.95 \\
& $\mathbf{1 3 . 2 5}$ & $\mathbf{2 8}$ & 340.85 \\
& & $\mathbf{3 0}$ & 335.15 \\
Rest of central section & & $\mathbf{3 4}$ & 323.05 \\
& $\mathbf{9 . 2 5}$ & $\mathbf{3 1}$ & 337.95 \\
& & $\mathbf{3 2}$ & 333.95 \\
& & $\mathbf{3 5}$ & 312.85 \\
& $\mathbf{5 . 2 5}$ & $\mathbf{2 4}$ & 334.85 \\
& & $\mathbf{2 6}$ & 326.95 \\
\hline
\end{tabular}


TableB5

Table B5

Air temperature at the exhaust fans,

\begin{tabular}{ccccc}
\hline & Zone & & Sensor & Temperature (K) \\
\hline \multirow{2}{*}{ Fans } & Wall A & $\mathbf{5 9}$ & 350.55 \\
& & Wall C & $\mathbf{6 0}$ & 351.15 \\
\hline
\end{tabular}

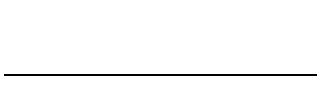

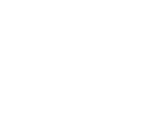

$\sqrt{2}+2$

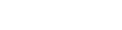

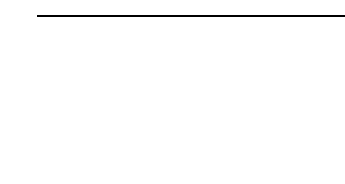

